\title{
Synthesis of Novel Symmetrical and Unsymmetrical o-Phthalic Acid Diamides
}

\author{
Padam Praveen Kumar, Yervala Dathu Reddy, Chittireddy Venkata Ramana Reddy, \\ Bhoomireddy Rama Devi, and Pramod Kumar Dubey
}

Department of Chemistry, Jawaharlal Nehru Technological University Hyderabad College of Engineering, Kukatpally, Hyderabad, Andhra Pradesh 500085, India

Correspondence should be addressed to Padam Praveen Kumar; padampraveenku@gmail.com

Received 23 January 2014; Revised 26 March 2014; Accepted 27 March 2014; Published 5 May 2014

Academic Editor: Joseph E. Saavedra

Copyright (C) 2014 Padam Praveen Kumar et al. This is an open access article distributed under the Creative Commons Attribution License, which permits unrestricted use, distribution, and reproduction in any medium, provided the original work is properly cited.

Phthalic anhydride was treated with secondary amines in acetic acid yielding 2-(diethyl (or) 4-alkylpiperazine or morpholine-1carbonyl) benzoic acids. The latter were reacted, again, with secondary amines and arylamines by using the coupling reagent HATU and $\mathrm{Et}_{3} \mathrm{~N}$ as a base in DMF giving the novel symmetrical o-phthalic acid diamides $\left[0-\mathrm{R}_{1} \mathrm{R}_{1} \mathrm{NCOC}_{6} \mathrm{H}_{4} \mathrm{CONR}_{1} \mathrm{R}_{1}\right]$, unsymmetrical ophthalic acid diamides $\left[0-\mathrm{R}_{1} \mathrm{R}_{1} \mathrm{NCOC}_{6} \mathrm{H}_{4} \mathrm{CONR}_{1} \mathrm{R}_{2}\right]$, and primary amidic-secondary amidic containing unsymmetrical o-phthalic acid diamides [o- $\mathrm{R}_{1} \mathrm{R}_{1} \mathrm{NCOC}_{6} \mathrm{H}_{4} \mathrm{CONHAr}$, respectively.

\section{Introduction}

Phthalic anhydride is used in the manufacture of dialkylphthalates $[1,2]$ which find application as plasticisers for polymers like polyvinyl chloride (PVC) and polyvinylacetate (PVA). It is used in the manufacture of phenolphthalein indicator [3, 4], anthraquinone [5] (a versatile, raw materials in the dye industry [6]), and metal phthalocyanines [7]. Phthalocyanine compounds are used in a variety of applications [7] in addition to their use as pigments, in paints [8] and in many types of dyestuffs [7]. Phthalic anhydride derivatives have been widely reported to possess beneficial pharmaceutical effects, like analgesic [9], anti-inflammatory [10] and antiviral effects [11].

Dunlap and Cummer reported [12] the preparation of symmetrical o-phthalic acid diamides [oArNHCOC ${ }_{6} \mathrm{H}_{4}$ CONHAr] by the reaction of phthaloyl dichloride with two moles of aniline in ether at RT. Dann et al. reported [13] the preparation of symmetrical o-phthalic acid diamides by the reaction of phthaloyl dichloride with two moles of aniline in the presence of sodium fluoride in benzene under reflux for $1 \mathrm{~h}$. de Toranzo and Brieux reported [14] the synthesis of unsymmetrical diamides $\left[\mathrm{ArNHCOC}_{6} \mathrm{H}_{4} \mathrm{CONHAr}^{1}\right]$ by the reaction of phthalphenylisoimide with anilines in ether at RT. Reynolds reported [15] that unsymmetrical diamides $\left[\mathrm{ArNHCOC}_{6} \mathrm{H}_{4} \mathrm{CONHAr}^{1}\right]$ can be made by the reaction of $\mathrm{N}$-arylphthalamic acid with the sodium salt of o- or p-methylaniline in an atmosphere of nitrogen for $1 \mathrm{~h}$ at $75^{\circ} \mathrm{C}$. However, these methods suffer from drawbacks such as long reaction times, excess use of organic solvents, harsh refluxing conditions, and preparation of difficult starting materials from phthalic anhydride by the reaction with primary amines in the presence of trifluoroacetic anhydride. Keeping these facts in mind, we wish to report our results on reactions of phthalic anhydride with primary and secondary amines using HATU as a coupling reagent. Probably, this appears to be the first ever case of facile preparation of symmetrical and unsymmetrical o-phthalic acid diamides. The use of HATU as a coupling agent has been reported in the literature for reactions such as amide bond formation in solid phase synthesis [16-18] and peptides synthesis [19]. However, its use in the preparation of diamides from phthalic anhydride with amines has probably not been reported so far. 
TABLE 1: Effect of coupling reagent, tertiary base, and temperature on condensation of $\mathbf{3 a}$ with $\mathbf{2} \mathbf{b}$ in DMF yielding $\mathbf{5 a}$.

\begin{tabular}{|c|c|c|c|c|c|}
\hline Entry & Coupling reagent & Tertiary base & Temp. $/{ }^{\circ} \mathrm{C}$ & Time/min & $5 \mathbf{a}(\%)$ \\
\hline 1 & HATU & $\mathrm{Et}_{3} \mathrm{~N}$ & $0-5$ & $40-45$ & 80 \\
\hline 2 & HATU & $\mathrm{Et}_{3} \mathrm{~N}$ & $\mathrm{RT}$ & $40-45$ & 78 \\
\hline 3 & HATU & $\mathrm{DBU}$ & $0-5$ & $55-65$ & 70 \\
\hline 4 & HATU & $\mathrm{DBU}$ & $\mathrm{RT}$ & $50-55$ & 70 \\
\hline 5 & HATU & $\mathrm{Et}_{3} \mathrm{~N}$ & $50-60$ & $35-40$ & 73 \\
\hline 6 & DCC & - & $0-5$ & $120-130$ & 45 \\
\hline 7 & DCC & - & $\mathrm{RT}$ & $100-110$ & 48 \\
\hline 8 & $\mathrm{DCC} / \mathrm{HOBt}$ & - & $0-5$ & $110-120$ & 50 \\
\hline 9 & $\mathrm{DCC} / \mathrm{HOBt}$ & - & $\mathrm{RT}$ & $100-110$ & 50 \\
\hline 10 & $\mathrm{DCC} / \mathrm{HOBt}$ & - & $50-60$ & $55-60$ & 72 \\
\hline 11 & $\mathrm{EDC} \cdot \mathrm{HCl} / \mathrm{HOBt}$ & $\mathrm{Et}_{3} \mathrm{~N}$ & $0-5$ & $80-85$ & 70 \\
\hline 12 & $\mathrm{EDC} \cdot \mathrm{HCl} / \mathrm{HOBt}$ & $\mathrm{Et}_{3} \mathrm{~N}$ & RT & $70-80$ & 70 \\
\hline 13 & $\mathrm{EDC} \cdot \mathrm{HCl} / \mathrm{HOBt}$ & $\mathrm{DBU}$ & $0-5$ & $70-80$ & 60 \\
\hline 14 & $\mathrm{EDC} \cdot \mathrm{HCl} / \mathrm{HOBt}$ & $\mathrm{DBU}$ & $\mathrm{RT}$ & $70-75$ & 65 \\
\hline 15 & $\mathrm{EDC} \cdot \mathrm{HCl} / \mathrm{HOBt}$ & $\mathrm{Et}_{3} \mathrm{~N}$ & $50-60$ & $65-70$ & 72 \\
\hline 16 & HBTU & $\mathrm{Et}_{3} \mathrm{~N}$ & $0-5$ & $70-75$ & 70 \\
\hline 17 & HBTU & $\mathrm{Et}_{3} \mathrm{~N}$ & $\mathrm{RT}$ & $65-70$ & 70 \\
\hline 18 & HBTU & $\mathrm{DBU}$ & $0-5$ & $70-80$ & 65 \\
\hline 19 & HBTU & DBU & $\mathrm{RT}$ & $65-75$ & 65 \\
\hline 20 & HBTU & $\mathrm{Et}_{3} \mathrm{~N}$ & $50-60$ & 50-55 & 70 \\
\hline 21 & PTSA & - & $0-5$ & $120-125$ & - \\
\hline 22 & PTSA & - & RT & $120-125$ & - \\
\hline 23 & PPA & - & 100 & $60-65$ & 40 \\
\hline
\end{tabular}

TABLE 2: Characterization data, reaction time, and yields of $\mathbf{3 a}-\mathbf{3 e}$ obtained $\mathbf{1}$ and $\mathbf{2 a - 2 e}$.

\begin{tabular}{|c|c|c|c|c|c|}
\hline Entry & Starting material used & Product obtained & Time (min) & Yield $^{\neq}$ & M.P $\left({ }^{\circ} \mathrm{C}\right)$ \\
\hline 1 & $2 a$ & $3 a$ & $10-12$ & 85 & $145-148$ \\
\hline 2 & $2 b$ & $3 b$ & $12-15$ & 85 & $>220$ \\
\hline 3 & $2 c$ & $3 c$ & $15-18$ & 83 & $>220$ \\
\hline 4 & $2 d$ & $3 d$ & $15-18$ & 80 & $>220$ \\
\hline 5 & $2 e$ & $3 e$ & $15-20$ & 81 & $>220$ \\
\hline
\end{tabular}

${ }^{\neq}$Refers to yields of crude products only.

\section{Results and Discussion}

Phthalic anhydride 1 was treated with the secondary amines 2a-2e in acetic acid at RT for 10-15 min resulting in the formation of 2-(diethyl (or) 4-alkylpiperazine (or) morpholine1-carbonyl)benzoic acid $\mathbf{3} \mathbf{a}-\mathbf{3} \mathbf{e}$. Reaction of $\mathbf{3} \mathbf{a}$ with the piperazine $\mathbf{2 b}$ in the presence of o-(7-azabenzotriazol-1-yl)-1,1,3,3tetramethyluroniumhexafluorophosphate (HATU) and $\mathrm{Et}_{3} \mathrm{~N}$ at $0-5^{\circ} \mathrm{C}$ for $40-45 \mathrm{~min}$ in $\mathrm{DMF}$ gave 5a. Alternatively, this compound was prepared by treating 2-(piperazine-1carbonyl)benzoic acid $\mathbf{3} \mathbf{b}$ withdiethylamine $\mathbf{2} \mathbf{a}$ by HATU and $\mathrm{Et}_{3} \mathrm{~N}$ at $0-5^{\circ} \mathrm{C}$ for $40-45 \mathrm{~min}$ in DMF to form N,Ndiethyl-2-(piperazine-1-carbonyl)benzamide 5a. This reaction was examined by carrying out the condensation of 2(diethylcarbonyl)benzoic acid $3 \mathbf{a}(1 \mathrm{mmol})$ with piperazine 2b $(1 \mathrm{mmol})$ in the presence different coupling reagents (HATU, EDC.HCl/HOBt (1-hydroxybenzotriazole), DCC (N,N'-dicyclohexylcarbodiimide), HBTU and PTSA (4methylbenzenesulfonic acid)) and tertiary bases $\left(\mathrm{Et}_{3} \mathrm{~N}\right.$ and
$\operatorname{DBU}(2,3,4,6,7,8,9,10$-octahydropyrimido [1, 2-a] azepine) at different temperatures in DMF as a solvent (Table 1) with a view to study the generalisation of condensation between $\mathbf{3}$ and $\mathbf{2}$. However, coupling of $\mathbf{3} \mathbf{a}$ with $\mathbf{2} \mathbf{b}$ in the presence of HATU and $\mathrm{Et}_{3} \mathrm{~N}$ at $0-5^{\circ} \mathrm{C}$ for $40-45 \mathrm{~min}$ in DMF was found to be the best method giving $\mathbf{5 a}$ in quality and yield $(\geq 80 \%)$ (Table 1 , entry $\mathbf{1}$ ).

Using the above-stated optimised conditions, $\mathbf{3} \mathbf{a}-\mathbf{3} \mathbf{e}$ were condensed into $2 \mathbf{a}-2 \mathbf{e}$ using HATU and $\mathrm{Et}_{3} \mathrm{~N}$ at $0-5^{\circ} \mathrm{C}$ for $40-$ 65 min in DMF yielding $\mathbf{4 a - 4 e}$ and $\mathbf{5 a}-\mathbf{5 j}$ (Scheme 1) (Tables 2 and 3 ) in excellent yield. The structures of the products have been established on the basis of their spectral and analytical data. (Please see experimental section).

Condensation of $3 \mathbf{a}-\mathbf{3} \mathbf{e}$ with arylamines $\mathbf{6 a}-\mathbf{6 e}$ in the presence of HATU and $\mathrm{Et}_{3} \mathrm{~N}$ at $0-5^{\circ} \mathrm{C}$ for $40-$ $55 \mathrm{~min}$ in DMF gave primary amidic-secondary amidic containing unsymmetrical o-phthalic acid diamides [o$\left.\mathrm{R}_{1} \mathrm{R}_{1} \mathrm{NCOC}_{6} \mathrm{H}_{4} \mathrm{CONHAr}\right] \quad \mathbf{7 a - 7 y}$ (Scheme 2) (Table 4). 


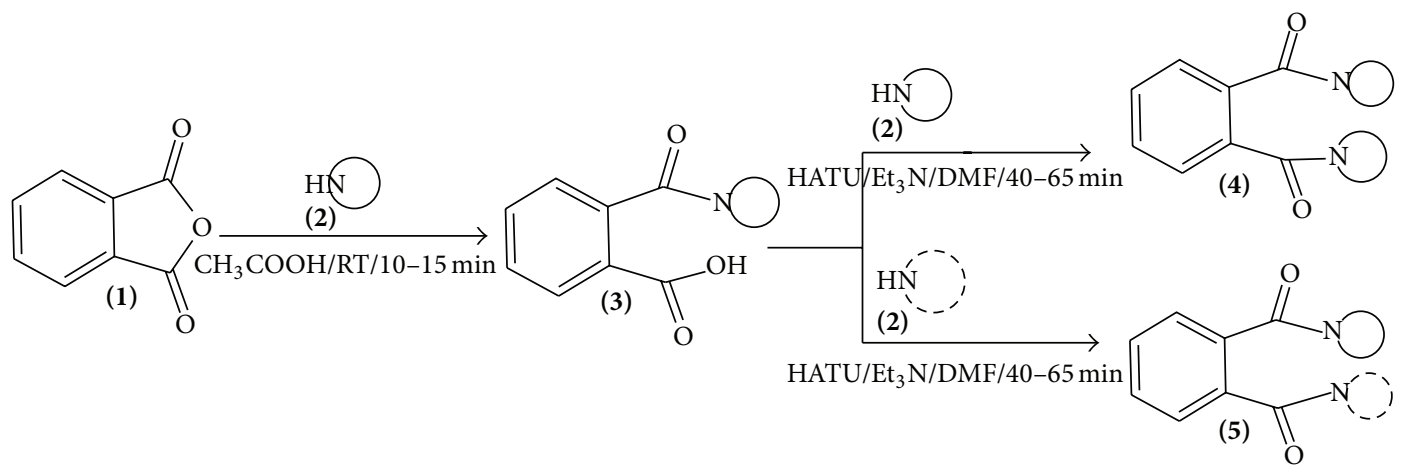

Scheme 1: Synthetic routes to $\mathbf{4 a}-\mathbf{4 e}$ and $\mathbf{5 a}-\mathbf{5 j}$.

The structures of the products have been established on the basis of their spectral and analytical data. An alternate protocol was attemptedto synthesize $7 \mathbf{a}-7 \mathbf{y}$ by treatment of $\mathbf{1}$ with aniline $\mathbf{6 a}$ in acetic acid at $0-5^{\circ} \mathrm{C}$ for $10-15 \mathrm{~min}$ which gave 2-(phenylcarbamoyl)benzoic acid $\mathbf{8} \mathbf{a}^{\mathbf{1 8}}$ and subsequent reaction of $\mathbf{8} \mathbf{a}$ with diethylamine $\mathbf{2} \mathbf{a}$ in the presence of HATU and $\mathrm{Et}_{3} \mathrm{~N}$ at RT for 20-25 min in DMF which resulted in the formation of 2-phenylisoindoline-1, 3-dione $9 a^{18}$.

\section{Conclusion}

In conclusion, we have developed novel syntheses of symmetrical $4 \mathbf{a}-\mathbf{4 e}$ and unsymmetrical $5 \mathbf{a}-5 \mathbf{j}$ and $7 \mathbf{a}-7 \mathbf{y}$ ophthalic acid diamides. This approach presents a simple and useful synthetic process which requires a few minutes of reaction time, easily available starting materials and straight forward and easy workup procedure. Probably, this appears to be the first ever case of facile preparation of symmetrical and unsymmetrical o-phthalic acid diamides. The use of HATU as a coupling agent has been reported in the literature for reactions such as amide bond formation in solid phase synthesis and peptides synthesis. However, its use in the preparation of diamides from phthalic anhydride with amines has probably not been reported so far. The overall yields of these compounds are very good.

\section{Materials and Methods}

Melting points are uncorrected and were determined in open capillary tubes in sulphuric acid bath, TLC was run on silica gel-G, visualization was done using iodine or UV light, and IR spectra were recorded using PerkinElmer 1000 instrument in $\mathrm{KBr}$ pellets. $1 \mathrm{HNMR}$ spectra were recorded in $\mathrm{DMSO}-\mathrm{d}_{6}$ using TMS as internal standard using $400 \mathrm{MHz}$ spectrometer. Mass spectra were recorded on Agilent-LCMS instrument under CI conditions and given by $Q+1$ values only. Starting 1, 2, and 6 were obtained from commercial sources and used as such.

4.1. Preparation of $\mathbf{3 a}-\mathbf{3 e}$. A mixture of $\mathbf{1 a}(10 \mathrm{mM}), \mathbf{2 a}-$ 2e $(10 \mathrm{Mm})$ and $\mathrm{CH}_{3} \mathrm{COOH}(20 \mathrm{~mL})$ was stirred at RT for
10-20 min. A colourless solid separated out from reaction mixture which was filtered, washed with hexane $(10 \mathrm{~mL})$, and dried. The crude product was recrystallized from suitable solvent to obtain $\mathbf{3 a - 3 e . ~}$

4.2. Preparation of $\mathbf{4 a - 4 e}$ \& $5 \boldsymbol{a}-5 \mathbf{j}$. A mixture of $\mathbf{3 a}-\mathbf{3 e}$ (10 mM), 2a-2e (10 mM) HATU (10 mM), $\mathrm{Et}_{3} \mathrm{~N}(10 \mathrm{mM})$, and DMF $(15 \mathrm{~mL})$ was stirred at $0-5^{\circ} \mathrm{C}$ for $40-65 \mathrm{~min}$. Then, icecold water $(50 \mathrm{~mL})$ was added to the reaction mixture. The separated solid was filtered, washed with water $(10 \mathrm{~mL})$, and dried. The product was recrystallized from a suitable solvent to obtain $4 \mathbf{a}-\mathbf{4 e}$ and $5 \mathbf{a}-\mathbf{5 j}$.

4.3. Preparation of $7 \boldsymbol{a}-7 \boldsymbol{y}$. A mixture of $\mathbf{3 a}-\mathbf{3 e}(10 \mathrm{mM})$, 6a-6e $(10 \mathrm{mM})$, HATU $(10 \mathrm{mM}), \mathrm{Et}_{3} \mathrm{~N}(10 \mathrm{mM})$, and DMF $(15 \mathrm{~mL})$ was stirred at $0-5^{\circ} \mathrm{C}$ for $40-55 \mathrm{~min}$. Then, icecold water $(50 \mathrm{~mL})$ was added to the reaction mixture. The separated solid was filtered, washed with water $(10 \mathrm{~mL})$, and dried. The product was recrystallized from a suitable solvent to obtain $7 \mathbf{a}-7 \mathbf{y}$.

\section{Supporting Information}

3a: IR (KBr): $3100-3400 \mathrm{~cm}^{-1}$ (broad medium, $-\mathrm{NH}$ and -OH groups put together), $1720 \mathrm{~cm}^{-1}$ (sharp, strong, -CO- of acid group), $1655 \mathrm{~cm}^{-1}$ (sharp, storng, -CO- of amide group); ${ }^{1} \mathrm{H}-\mathrm{NMR}: \delta 0.8\left(\mathrm{t}, 3 \mathrm{H},-\mathrm{CH}_{3}\right), \delta 1.2\left(\mathrm{t}, 3 \mathrm{H},-\mathrm{CH}_{3}\right), \delta 3.0(\mathrm{q}$, $\left.2 \mathrm{H},-\mathrm{CH}_{2}\right), \delta 3.6\left(\mathrm{q}, 2 \mathrm{H},-\mathrm{CH}_{2}\right), 7.0-8.0(\mathrm{~m}, 4 \mathrm{H}, \mathrm{Ar}-\mathrm{H}), 13.00$ (s, 1H, -COOH, D2O exchangeable), 10.12 (s, 1H, -NH, D2O exchangeable). ${ }^{13} \mathrm{C}$ NMR (DMSO- $\mathrm{d}_{6}, 400 \mathrm{MHz}$ ): 12.3, 41.4, $123.1,128.5,129.3,129.5,160.2,165.5$. Ms: $m / z=222\left(\mathrm{M}^{+}{ }_{+}\right.$ $1)$.

3b: IR (KBr): $3100-3400 \mathrm{~cm}^{-1}$ (broad medium, $-\mathrm{NH}$ and -OH groups put together), $1725 \mathrm{~cm}^{-1}$ (sharp, strong, -CO- of acid group), $1670 \mathrm{~cm}^{-1}$ (sharp, storng, -CO- of amide group); ${ }^{1} \mathrm{H}-\mathrm{NMR}: \delta 2.2(\mathrm{~s}, 1 \mathrm{H},-\mathrm{NH}), \delta 3.0\left(\mathrm{t}, 2 \mathrm{H},-\mathrm{CH}_{2}\right), \delta 3.2(\mathrm{t}, 2 \mathrm{H}$, $\left.-\mathrm{CH}_{2}\right), \delta 3.4\left(\mathrm{t}, 2 \mathrm{H},-\mathrm{CH}_{2}\right), \delta 3.8\left(\mathrm{t}, 2 \mathrm{H},-\mathrm{CH}_{2}\right), 7.0-8.0(\mathrm{~m}$, $4 \mathrm{H}, \mathrm{Ar}-\mathrm{H}), 13.00$ (s, 1H, -COOH, D2O exchangeable). ${ }^{13} \mathrm{C}$ NMR (DMSO-d ${ }_{6}, 400 \mathrm{MHz}$ ): 49.4, 50.1, 51.4, 51.9, 124.1, 125.5, 127.3, 128.5, 161.2, 164.8. Ms: $m / z=235\left(\mathrm{M}^{+}+1\right)$. 

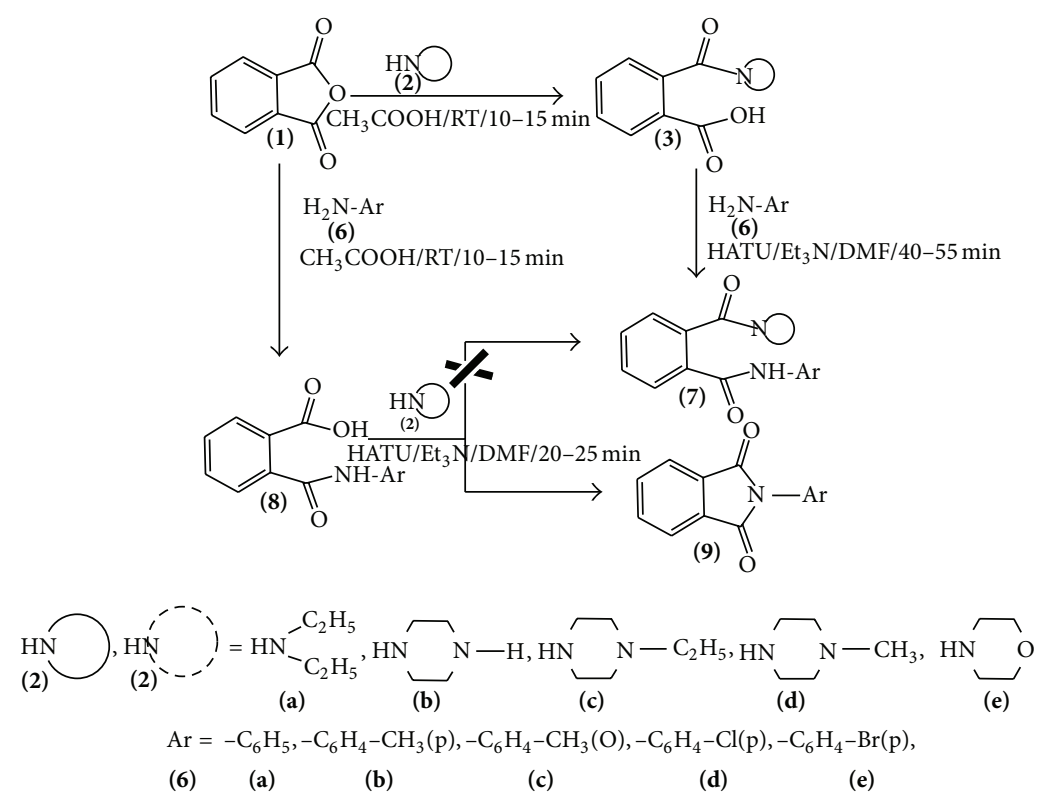

Plausible mechanism for 4, 5, and 7 from 3 :

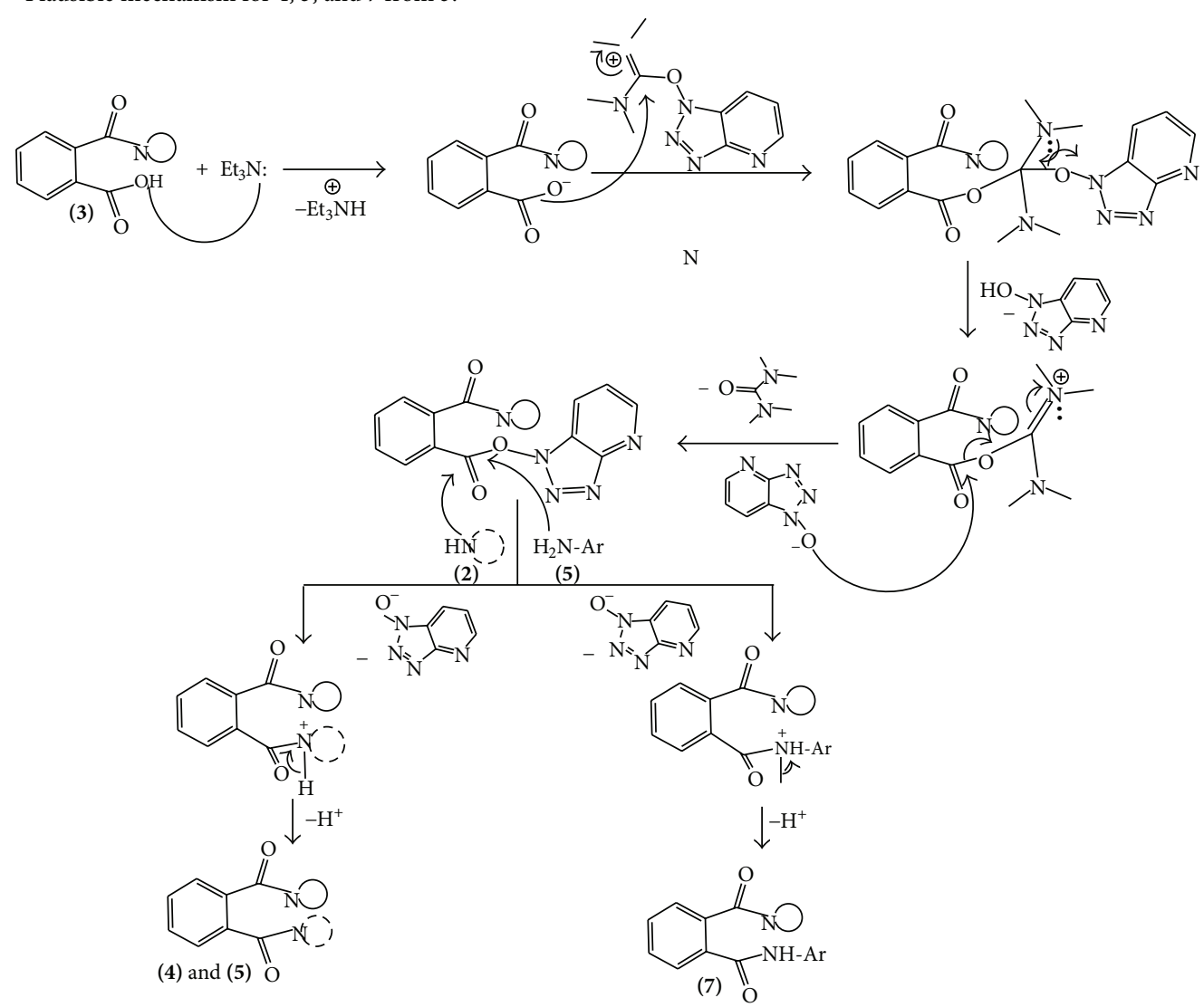

Scheme 2: Synthetic routes to $7 \mathbf{a}-7 \mathbf{y}$.

3c: IR (KBr): $3100-3400 \mathrm{~cm}^{-1}$ (broad medium, $-\mathrm{NH}$ and -OH groups put together), $1730 \mathrm{~cm}^{-1}$ (sharp, strong, $-\mathrm{CO}-$ of acid group), $1655 \mathrm{~cm}^{-1}$ (sharp, storng, $-\mathrm{CO}-$ of amide group); ${ }^{1} \mathrm{H}$-NMR: $\delta 1.2\left(\mathrm{t}, 3 \mathrm{H},-\mathrm{CH}_{3}\right), \delta 2.6\left(\mathrm{q}, 2 \mathrm{H},-\mathrm{CH}_{2}\right), \delta 3.0(\mathrm{t}$, $\left.2 \mathrm{H},-\mathrm{CH}_{2}\right), \delta 3.2\left(\mathrm{t}, 2 \mathrm{H},-\mathrm{CH}_{2}\right), \delta 3.4\left(\mathrm{t}, 2 \mathrm{H},-\mathrm{CH}_{2}\right), \delta 3.8(\mathrm{t}$, $\left.2 \mathrm{H},-\mathrm{CH}_{2}\right), 7.0-8.0(\mathrm{~m}, 4 \mathrm{H}, \mathrm{Ar}-\mathrm{H}), 13.2(\mathrm{~s}, 1 \mathrm{H},-\mathrm{COOH}, \mathrm{D} 2 \mathrm{O}$ exchangeable). ${ }^{13} \mathrm{C}$ NMR (DMSO-d $\left.{ }_{6}, 400 \mathrm{MHz}\right): 12.5,49.4$, 50.1, 50.9, 51.9, 52.2, 123.1, 124.5, 125.3, 127.5, 163.2, 164.8. Ms: $\mathrm{m} / z=263\left(\mathrm{M}^{+}+1\right)$.

3d: IR (KBr): $3100-3400 \mathrm{~cm}^{-1}$ (broad medium, $-\mathrm{NH}$ and $-\mathrm{OH}$ groups put together), $1720 \mathrm{~cm}^{-1}$ (sharp, strong, -COof acid group), $1660 \mathrm{~cm}^{-1}$ (sharp, storng, $-\mathrm{CO}-$ of amide 
TABLE 3: Characterization data, reaction time, and yields of $\mathbf{4 a - 4 e}$ and $\mathbf{5 a - 5 j}$ obtained from $\mathbf{3 a}-\mathbf{3 e}$ and $\mathbf{2 a - 2 e}$.

\begin{tabular}{|c|c|c|c|c|c|c|}
\hline \multirow{2}{*}{$\begin{array}{l}\text { Entry } \\
1\end{array}$} & \multicolumn{2}{|c|}{ Starting material used } & \multirow{2}{*}{$\begin{array}{c}\text { Product obtained } \\
4 \mathrm{a}\end{array}$} & \multirow{2}{*}{$\begin{array}{c}\text { Time (min) } \\
40-45\end{array}$} & \multirow{2}{*}{$\begin{array}{c}\text { Yield }^{\neq} \\
85\end{array}$} & \multirow{2}{*}{$\begin{array}{c}\text { M.P }\left({ }^{\circ} \mathrm{C}\right) \\
>220\end{array}$} \\
\hline & $3 \mathbf{a}$ & $2 a$ & & & & \\
\hline 2 & $3 b$ & $2 \mathbf{b}$ & $4 b$ & $40-45$ & 85 & $>220$ \\
\hline 3 & $3 c$ & $2 c$ & $4 c$ & $50-55$ & 80 & $>220$ \\
\hline 4 & $3 d$ & $2 d$ & $4 d$ & $50-55$ & 80 & $>220$ \\
\hline 5 & $3 e$ & $2 e$ & $4 e$ & $40-45$ & 80 & $>220$ \\
\hline 6 & $3 \mathbf{a}$ & $2 b$ & $5 a$ & $40-45$ & 85 & $>220$ \\
\hline 7 & $3 \mathbf{a}$ & $2 c$ & $5 \mathbf{b}$ & $50-55$ & 81 & $110-112$ \\
\hline 8 & $3 \mathbf{a}$ & $2 d$ & $5 c$ & $50-55$ & 84 & $115-118$ \\
\hline 9 & $3 \mathbf{a}$ & $2 e$ & $5 d$ & $50-55$ & 85 & $80-82$ \\
\hline 10 & $3 \mathbf{b}$ & $2 a$ & $5 \mathbf{a}$ & $40-45$ & 83 & $>220$ \\
\hline 11 & $3 b$ & $2 \mathrm{c}$ & $5 e$ & $50-55$ & 84 & $>220$ \\
\hline 12 & $3 b$ & $2 d$ & $5 f$ & $50-55$ & 85 & $>220$ \\
\hline 13 & $3 \mathbf{b}$ & $2 e$ & $5 g$ & $60-65$ & 85 & $85-87$ \\
\hline 14 & $3 c$ & $2 a$ & $5 b$ & $60-65$ & 81 & $110-112$ \\
\hline 15 & $3 c$ & $2 \mathbf{b}$ & $5 e$ & $50-55$ & 83 & $>220$ \\
\hline 16 & $3 c$ & $2 d$ & $5 \mathrm{~h}$ & $50-55$ & 85 & $>220$ \\
\hline 17 & $3 c$ & $2 e$ & $5 \mathbf{i}$ & $50-55$ & 85 & $90-92$ \\
\hline 18 & $3 d$ & $2 a$ & $5 c$ & $60-65$ & 80 & $115-118$ \\
\hline 19 & $3 d$ & $2 b$ & $5 f$ & $50-55$ & 80 & $>220$ \\
\hline 20 & $3 d$ & $2 c$ & $5 \mathrm{~h}$ & $40-45$ & 85 & $>220$ \\
\hline 21 & $3 d$ & $2 e$ & $5 \mathbf{j}$ & $40-45$ & 83 & $>220$ \\
\hline 22 & $3 e$ & $2 a$ & $5 d$ & $40-45$ & 80 & $80-82$ \\
\hline 23 & $3 e$ & $2 b$ & $5 \mathrm{~g}$ & $50-55$ & 84 & $85-87$ \\
\hline 24 & $3 e$ & $2 c$ & $5 \mathbf{i}$ & $50-55$ & 84 & $90-92$ \\
\hline 25 & $3 e$ & $2 d$ & $5 \mathbf{j}$ & $40-45$ & 83 & $>220$ \\
\hline
\end{tabular}

${ }^{\neq}$Refers to yields of crude products only.

group); ${ }^{1} \mathrm{H}-\mathrm{NMR}: \delta 1.6\left(\mathrm{t}, 3 \mathrm{H},-\mathrm{CH}_{3}\right), \delta 3.0\left(\mathrm{t}, 2 \mathrm{H},-\mathrm{CH}_{2}\right), \delta$ $3.2\left(\mathrm{t}, 2 \mathrm{H},-\mathrm{CH}_{2}\right), \delta 3.4\left(\mathrm{t}, 2 \mathrm{H},-\mathrm{CH}_{2}\right), \delta 3.8\left(\mathrm{t}, 2 \mathrm{H},-\mathrm{CH}_{2}\right), 7.0-$ 8.0 (m, 4H, Ar-H), 13.1 (s, 1H, - $\mathrm{COOH}, \mathrm{D} 2 \mathrm{O}$ exchangeable). ${ }^{13}$ C NMR (DMSO-d $\left.\mathrm{d}_{6}, 400 \mathrm{MHz}\right): 39.4,55.1,55.9,55.9,55.2$, 126.1, 127.5, 128.3, 129.5, 160.2, 165.8. Ms: $m / z=249\left(\mathrm{M}^{+}+1\right)$.

3e: IR (KBr): $3100-3400 \mathrm{~cm}^{-1}$ (broad medium, $-\mathrm{NH}$ and -OH groups put together), $1720 \mathrm{~cm}^{-1}$ (sharp, strong, $-\mathrm{CO}-$ of acid group), $1655 \mathrm{~cm}^{-1}$ (sharp, storng, $-\mathrm{CO}-$ of amide group); ${ }^{1} \mathrm{H}-\mathrm{NMR}: \delta 3.0\left(\mathrm{t}, 2 \mathrm{H},-\mathrm{CH}_{2}\right), \delta 3.2\left(\mathrm{t}, 2 \mathrm{H},-\mathrm{CH}_{2}\right), \delta 3.4(\mathrm{t}$, $\left.2 \mathrm{H},-\mathrm{CH}_{2}\right), \delta 3.8\left(\mathrm{t}, 2 \mathrm{H},-\mathrm{CH}_{2}\right), 7.0-8.0(\mathrm{~m}, 4 \mathrm{H}, \mathrm{Ar}-\mathrm{H}), 13.1$ (s, $1 \mathrm{H},-\mathrm{COOH}, \mathrm{D} 2 \mathrm{O}$ exchangeable). ${ }^{13} \mathrm{C}$ NMR (DMSO-d ${ }_{6}$, $400 \mathrm{MHz}$ ): 50.2, 50.6, 71.9, 72.2, 125.1, 125.5, 126.3, 127.5, 162.2, 164.8. Ms: $m / z=236\left(\mathrm{M}^{+}+1\right)$.

4a: IR (KBr): $3100-3400 \mathrm{~cm}^{-1}$ (broad medium, $-\mathrm{NH}-$ ), $1680 \mathrm{~cm}^{-1}$ (sharp, strong, -CO- of amide group), $1665 \mathrm{~cm}^{-1}$ (sharp, strong, $-\mathrm{CO}-$ of amide group); ${ }^{1} \mathrm{H}-\mathrm{NMR}: \delta 1.2(\mathrm{t}, 6 \mathrm{H}$, $\left.-\mathrm{CH}_{3},-\mathrm{CH}_{3}\right), \delta 1.4\left(\mathrm{t}, 6 \mathrm{H},-\mathrm{CH}_{3},-\mathrm{CH}_{3}\right), \delta 2.8\left(\mathrm{q}, 4 \mathrm{H},-\mathrm{CH}_{2}\right.$, $\left.-\mathrm{CH}_{2}\right) \delta 3.2\left(\mathrm{q}, 4 \mathrm{H},-\mathrm{CH}_{2},-\mathrm{CH}_{2}\right), 7.0-8.0(\mathrm{~m}, 4 \mathrm{H}, \mathrm{Ar}-\mathrm{H}) .{ }^{12} \mathrm{C}$ NMR (DMSO-d $\mathrm{d}_{6}, 400 \mathrm{MHz}$ ): 12.9, 14.1, 31.6, 36.7, 39.1, 43.5, 125.3, 126.5, 127.1, 129.3, 163.6, 169.6. Ms: $m / z=277\left(\mathrm{M}^{+}+1\right)$.

4b: IR (KBr): $3100-3400 \mathrm{~cm}^{-1}$ (broad medium, $-\mathrm{NH}-$ ), $1685 \mathrm{~cm}^{-1}$ (sharp, strong, -CO- of amide group), $1665 \mathrm{~cm}^{-1}$ (sharp, strong, -CO- of amide group); ${ }^{1} \mathrm{H}-\mathrm{NMR}$ : $\delta 2.2$ (s, $2 \mathrm{H},-\mathrm{NH},-\mathrm{NH}), \delta 3.0\left(\mathrm{t}, 8 \mathrm{H}\right.$, Four $-\mathrm{CH}_{2}$ groups), $\delta 3.4$ (t, 8H, Four $-\mathrm{CH}_{2}$ groups), 7.0-8.0 (m, $\left.4 \mathrm{H}, \mathrm{Ar}-\mathrm{H}\right) .{ }^{13} \mathrm{C}$ NMR (DMSO-d $\mathrm{d}_{6}, 400 \mathrm{MHz}$ ): 47.4, 48.6, 49.7, 50.9, 51.5, 52.4, 125.3, 125.5, 127.1, 128.6, 164.3, 167.6. Ms: $m / z=303\left(\mathrm{M}^{+}+1\right)$.

4c: IR (KBr): $3100-3400 \mathrm{~cm}^{-1}$ (broad medium, $-\mathrm{NH}-$ ), $1660 \mathrm{~cm}^{-1}$ (sharp, strong, $-\mathrm{CO}$ - of amide group), $1665 \mathrm{~cm}^{-1}$ (sharp, strong, -CO- of amide group); ${ }^{1} \mathrm{H}-\mathrm{NMR}: \delta 1.3$ (t, $6 \mathrm{H}$, $\left.-\mathrm{CH}_{3},-\mathrm{CH}_{3}\right), \delta 2.8\left(\mathrm{q}, 4 \mathrm{H},-\mathrm{CH}_{2},-\mathrm{CH}_{2}\right), \delta 3.2(\mathrm{t}, 8 \mathrm{H}$, Four $-\mathrm{CH}_{2}$ groups), $\delta 3.2$ (t, $8 \mathrm{H}$, Four $-\mathrm{CH}_{2}$ groups), 7.0-8.0 (m, $4 \mathrm{H}, \mathrm{Ar}-\mathrm{H}) .{ }^{13} \mathrm{C}$ NMR (DMSO-d 6 , $400 \mathrm{MHz}$ ): 12.3, 16.1, 46.4, 47.6, 48.7, 49.1, 50.5, 51.4, 123.3, 124.5, 128.1, 128.9, 164.6, 168.6. Ms: $m / z=359\left(\mathrm{M}^{+}+1\right)$.

4d: IR (KBr): $3100-3400 \mathrm{~cm}^{-1}$ (broad medium, $-\mathrm{NH}-$ ), $1670 \mathrm{~cm}^{-1}$ (sharp, strong, -CO- of amide group), $1665 \mathrm{~cm}^{-1}$ (sharp, strong, -CO- of amide group); ${ }^{1} \mathrm{H}-\mathrm{NMR}: \delta 1.4(\mathrm{t}$, $\left.6 \mathrm{H},-\mathrm{CH}_{3},-\mathrm{CH}_{3}\right), \delta 3.0\left(\mathrm{t}, 8 \mathrm{H}\right.$, Four $-\mathrm{CH}_{2}$ groups), $\delta 3.2(\mathrm{t}$, $8 \mathrm{H}$, Four $-\mathrm{CH}_{2}$ groups), 7.0-8.0 (m, $\left.4 \mathrm{H}, \mathrm{Ar}-\mathrm{H}\right) .{ }^{13} \mathrm{C}$ NMR (DMSO-d ${ }_{6}, 400 \mathrm{MHz}$ ): 32.3, 33.4, 48.4, 48.9, 49.7, 50.5, 52.4, 55.3, 125.3, 125.6, 128.3, 129.9, 165.2, 169.3. Ms: $m / z=331$ $\left(\mathrm{M}^{+.}+1\right)$.

4e: IR (KBr): $3100-3400 \mathrm{~cm}^{-1}$ (broad medium, $-\mathrm{NH}-$ ), $1675 \mathrm{~cm}^{-1}$ (sharp, strong, -CO- of amide group), $1665 \mathrm{~cm}^{-1}$ (sharp, strong, -CO- of amide group); ${ }^{1} \mathrm{H}-\mathrm{NMR}: \delta 3.0(\mathrm{t}, 8 \mathrm{H}$, 
TABLE 4: Characterization data reaction time and yield of $7 \mathbf{a}-7 \mathbf{y}$ obtained from $3 \mathbf{a}-\mathbf{3 e}$ and $\mathbf{6 a}-\mathbf{6} \mathbf{e}$.

\begin{tabular}{|c|c|c|c|c|c|c|}
\hline Entry & & & Product obtained & Time (min) & Yield $^{\neq}$ & M.P $\left({ }^{\circ} \mathrm{C}\right)$ \\
\hline 1 & $3 \mathbf{a}$ & $6 a$ & $7 a$ & $40-45$ & 85 & $115-118$ \\
\hline 2 & $3 b$ & $6 a$ & $7 \mathbf{b}$ & $50-55$ & 82 & $120-123$ \\
\hline 3 & $3 c$ & $6 a$ & $7 \mathrm{c}$ & $40-45$ & 84 & $123-125$ \\
\hline 4 & $3 d$ & $6 a$ & $7 d$ & $50-55$ & 85 & $>220$ \\
\hline 5 & $3 e$ & $6 a$ & $7 e$ & $50-55$ & 80 & $126-128$ \\
\hline 6 & $3 a$ & $6 b$ & $7 f$ & $40-45$ & 83 & $128-130$ \\
\hline 7 & $3 \mathbf{b}$ & $6 b$ & $7 \mathrm{~g}$ & $40-45$ & 82 & $138-140$ \\
\hline 8 & $3 c$ & $6 b$ & $7 \mathbf{h}$ & $50-55$ & 82 & $120-123$ \\
\hline 9 & $3 d$ & $6 b$ & $7 \mathbf{i}$ & $50-55$ & 85 & $>220$ \\
\hline 10 & $3 e$ & $6 b$ & $7 \mathbf{j}$ & $40-45$ & 80 & $122-124$ \\
\hline 11 & $3 a$ & $6 c$ & $7 \mathbf{k}$ & $50-55$ & 82 & $120-124$ \\
\hline 12 & $3 b$ & $6 c$ & 71 & $40-45$ & 85 & $130-132$ \\
\hline 13 & $3 c$ & $6 c$ & $7 \mathrm{~m}$ & $50-55$ & 85 & $170-174$ \\
\hline 14 & $3 d$ & $6 c$ & $7 \mathbf{n}$ & $50-55$ & 80 & $>220$ \\
\hline 15 & $3 e$ & $6 c$ & 70 & $40-45$ & 80 & $140-143$ \\
\hline 16 & $3 a$ & $6 d$ & $7 \mathbf{p}$ & $40-45$ & 80 & $125-128$ \\
\hline 17 & $3 b$ & $6 d$ & $7 q$ & $50-55$ & 82 & $135-137$ \\
\hline 18 & $3 c$ & 6d & $7 \mathbf{r}$ & $50-55$ & 82 & $180-183$ \\
\hline 19 & $3 d$ & $6 d$ & $7 \mathrm{~s}$ & $40-45$ & 80 & $>220$ \\
\hline 20 & $3 e$ & 6d & $7 t$ & $40-45$ & 85 & $142-145$ \\
\hline 21 & $3 a$ & $6 e$ & $7 \mathbf{u}$ & $40-45$ & 84 & $128-130$ \\
\hline 22 & $3 b$ & $6 e$ & $7 \mathbf{v}$ & $40-45$ & 85 & $133-135$ \\
\hline 23 & $3 c$ & $6 e$ & $7 w$ & $50-55$ & 80 & $190-192$ \\
\hline 24 & $3 d$ & $6 e$ & $7 \mathbf{x}$ & $50-55$ & 82 & $>220$ \\
\hline 25 & $3 e$ & $6 e$ & $7 y$ & $40-45$ & 84 & 145-148 \\
\hline
\end{tabular}

${ }^{\neq}$Refers to yields of crude products only.

Four $-\mathrm{CH}_{2}$ groups), $\delta 3.2$ (t, $8 \mathrm{H}$, Four $-\mathrm{CH}_{2}$ groups), 7.0-8.0 (m, 4H, Ar-H). ${ }^{13} \mathrm{C}$ NMR (DMSO-d 6 , $400 \mathrm{MHz}$ ): 49.3, 49.9, $50.7,52.8,55.9,56.8,125.4,126.3,127.4,128.9,164.2,167.3 . ~ M s:$ $m / z=305\left(\mathrm{M}^{+\cdot}+1\right)$.

5a: IR (KBr): $3100-3400 \mathrm{~cm}^{-1}$ (broad medium, $-\mathrm{NH}-$ ), $1690 \mathrm{~cm}^{-1}$ (sharp, strong, -CO- of amide group), $1660 \mathrm{~cm}^{-1}$ (sharp, strong, -CO- of amide group); ${ }^{1} \mathrm{H}-\mathrm{NMR}: \delta 1.0-1.2(\mathrm{t}$, $\left.6 \mathrm{H},-\mathrm{CH}_{3},-\mathrm{CH}_{3}\right), \delta 2.2(\mathrm{~s}, 1 \mathrm{H},-\mathrm{NH}), \delta 3.0\left(\mathrm{t}, 4 \mathrm{H},-\mathrm{CH}_{2},-\right.$ $\left.\mathrm{CH}_{2}\right), \delta 3.2\left(\mathrm{t}, 4 \mathrm{H},-\mathrm{CH}_{2},-\mathrm{CH}_{2}\right), \delta 3.4\left(\mathrm{q}, 2 \mathrm{H},-\mathrm{CH}_{2}\right), \delta 3.6(\mathrm{q}$, $\left.2 \mathrm{H},-\mathrm{CH}_{2},-\mathrm{CH}_{2}\right), 7.0-8.0(\mathrm{~m}, 4 \mathrm{H}, \mathrm{Ar}-\mathrm{H}) .{ }^{13} \mathrm{C}$ NMR (DMSO$\left.\mathrm{d}_{6}, 400 \mathrm{MHz}\right): 12.9,31.7,43.5,44.6,51.1,52.5,123.1,124.3,128.3$, 129.6, 161.7, 165.5. Ms: $m / z=290\left(\mathrm{M}^{+}+1\right)$.

5b: IR (KBr): $3100-3400 \mathrm{~cm}^{-1}$ (broad medium, $-\mathrm{NH}-$ ), $1680 \mathrm{~cm}^{-1}$ (sharp, strong, -CO- of amide group), $1650 \mathrm{~cm}^{-1}$ (sharp, strong, -CO- of amide group); ${ }^{1} \mathrm{H}-\mathrm{NMR}$ : $\delta 1.0-1.2(\mathrm{t}$, $\left.6 \mathrm{H},-\mathrm{CH}_{3},-\mathrm{CH}_{3}\right), \delta 1.4\left(\mathrm{t}, 3 \mathrm{H},-\mathrm{CH}_{3}\right), \delta 2.2\left(\mathrm{q}, 2 \mathrm{H},-\mathrm{CH}_{2}\right)$, $\delta 3.0\left(\mathrm{t}, 4 \mathrm{H},-\mathrm{CH}_{2},-\mathrm{CH}_{2}\right), \delta 3.2\left(\mathrm{t}, 4 \mathrm{H},-\mathrm{CH}_{2},-\mathrm{CH}_{2}\right), \delta 3.4$ $\left(\mathrm{q}, 2 \mathrm{H},-\mathrm{CH}_{2}\right), \delta 3.6\left(\mathrm{q}, 2 \mathrm{H},-\mathrm{CH}_{2},-\mathrm{CH}_{2}\right), 7.0-8.0(\mathrm{~m}, 4 \mathrm{H}$, Ar-H). ${ }^{13}$ C NMR (DMSO-d 6 , $\left.400 \mathrm{MHz}\right): 12.9,13.6,31.5,44.5$, 45.6, 48.6, 54.1, 55.5, 123.6, 125.3, 128.3, 129.6, 162.7, 165.4. Ms: $m / z=318\left(\mathrm{M}^{+\cdot}+1\right)$.

5c: IR (KBr): $3100-3400 \mathrm{~cm}^{-1}$ (broad medium, $-\mathrm{NH}-$ ), $1695 \mathrm{~cm}^{-1}$ (sharp, strong, -CO- of amide group), $1655 \mathrm{~cm}^{-1}$ (sharp, strong, -CO- of amide group); ${ }^{1} \mathrm{H}-\mathrm{NMR}: \delta 1.0-1.2(\mathrm{t}$, $\left.6 \mathrm{H},-\mathrm{CH}_{3},-\mathrm{CH}_{3}\right), \delta 1.8\left(\mathrm{t}, 3 \mathrm{H},-\mathrm{CH}_{3}\right), \delta 3.0\left(\mathrm{t}, 4 \mathrm{H},-\mathrm{CH}_{2},-\right.$ $\left.\mathrm{CH}_{2}\right), \delta 3.2\left(\mathrm{t}, 4 \mathrm{H},-\mathrm{CH}_{2},-\mathrm{CH}_{2}\right), \delta 3.4\left(\mathrm{q}, 2 \mathrm{H},-\mathrm{CH}_{2}\right), \delta 3.6(\mathrm{q}$, $\left.2 \mathrm{H},-\mathrm{CH}_{2},-\mathrm{CH}_{2}\right), 7.0-8.0(\mathrm{~m}, 4 \mathrm{H}, \mathrm{Ar}-\mathrm{H}) .{ }^{13} \mathrm{C}$ NMR (DMSO$\left.\mathrm{d}_{6}, 400 \mathrm{MHz}\right): 13.9,32.7,41.5,44.6,45.5,53.1,54.5,122.3,125.3$, 129.2, 129.9, 164.7, 166.4. Ms: $m / z=304\left(\mathrm{M}^{+.}+1\right)$.

5d: IR (KBr): $3100-3400 \mathrm{~cm}^{-1}$ (broad medium, $-\mathrm{NH}-$ ), $1680 \mathrm{~cm}^{-1}$ (sharp, strong, -CO- of amide group), $1655 \mathrm{~cm}^{-1}$ (sharp, strong, -CO- of amide group); ${ }^{1} \mathrm{H}-\mathrm{NMR}: \delta 1.0-1.2(\mathrm{t}$, $\left.6 \mathrm{H},-\mathrm{CH}_{3},-\mathrm{CH}_{3}\right), \delta 3.0\left(\mathrm{t}, 4 \mathrm{H},-\mathrm{CH}_{2},-\mathrm{CH}_{2}\right), \delta 3.2(\mathrm{t}, 4 \mathrm{H},-$ $\left.\mathrm{CH}_{2},-\mathrm{CH}_{2}\right), \delta 3.4\left(\mathrm{q}, 2 \mathrm{H},-\mathrm{CH}_{2}\right), \delta 3.6\left(\mathrm{q}, 2 \mathrm{H},-\mathrm{CH}_{2},-\mathrm{CH}_{2}\right)$, 7.0-8.0 (m, 4H, Ar-H). ${ }^{13} \mathrm{C} \mathrm{NMR}$ (DMSO-d 6 , $\left.400 \mathrm{MHz}\right): 13.2$, 33.4, 44.3, 45.2, 50.1, 52.4, 124.2, 123.5, 125.4, 125.7, 160.3, 165.6. Ms: $m / z=291\left(\mathrm{M}^{+\cdot}+1\right)$.

5e: IR (KBr): $3100-3400 \mathrm{~cm}^{-1}$ (broad medium, $-\mathrm{NH}-$ ), $1690 \mathrm{~cm}^{-1}$ (sharp, strong, -CO- of amide group), $1665 \mathrm{~cm}^{-1}$ (sharp, strong, -CO- of amide group); ${ }^{1} \mathrm{H}-\mathrm{NMR}$ : $\delta 1.4(\mathrm{t}, 3 \mathrm{H}$, $\left.-\mathrm{CH}_{3}\right), \delta 2.2\left(\mathrm{q}, 2 \mathrm{H},-\mathrm{CH}_{2}\right), \delta 2.2(\mathrm{~s}, 1 \mathrm{H},-\mathrm{NH}), \delta 2.8-3.6(\mathrm{t}$, $16 \mathrm{H}$, eight $-\mathrm{CH}_{2}$ groups), 7.0-8.0 (m, $\left.4 \mathrm{H}, \mathrm{Ar}-\mathrm{H}\right) .{ }^{13} \mathrm{C} \mathrm{NMR}$ (DMSO-d ${ }_{6}, 400 \mathrm{MHz}$ ): 12.4, 29.4, 30.2, 31.7, 33.4, 34.3, 42.5, 43.6, 50.2, 51.2, 124.1, 125.2, 127.3, 129.3, 160.3, 164.2. Ms: $\mathrm{m} / z=$ $331\left(\mathrm{M}^{+\cdot}+1\right)$.

5f: IR (KBr): $3100-3400 \mathrm{~cm}^{-1}$ (broad medium, $-\mathrm{NH}-$ ), $1690 \mathrm{~cm}^{-1}$ (sharp, strong, $-\mathrm{CO}-$ of amide group), $1650 \mathrm{~cm}^{-1}$ 
(sharp, strong, -CO- of amide group); ${ }^{1} \mathrm{H}-\mathrm{NMR}: \delta 1.6(\mathrm{t}$, $\left.3 \mathrm{H},-\mathrm{CH}_{3}\right), \delta 2.2(\mathrm{~s}, 1 \mathrm{H},-\mathrm{NH}), \delta 2.8-3.6(\mathrm{t}, 16 \mathrm{H}$, eight $\mathrm{CH}_{2}$ groups), 7.0-8.0 (m, 4H, Ar-H). ${ }^{13} \mathrm{C}$ NMR (DMSO-d $\mathrm{d}_{6}$, $400 \mathrm{MHz}): 28.4,31.4,32.5,33.3,35.4,41.4,42.4,51.4,52.3$, 125.2, 126.1, 128.3, 129.2, 161.6, 165.1. Ms: $m / z=317\left(\mathrm{M}^{+.}+1\right)$.

5g: IR (KBr): $3100-3400 \mathrm{~cm}^{-1}$ (broad medium, $-\mathrm{NH}-$ ), $1680 \mathrm{~cm}^{-1}$ (sharp, strong, -CO- of amide group), $1655 \mathrm{~cm}^{-1}$ (sharp, strong, -CO- of amide group); ${ }^{1} \mathrm{H}-\mathrm{NMR}$ : $\delta 2.2(\mathrm{~s}, 1 \mathrm{H}$, $-\mathrm{NH}), \delta 2.8-3.6\left(\mathrm{t}, 16 \mathrm{H}\right.$, eight $-\mathrm{CH}_{2}$ groups), $7.0-8.0(\mathrm{~m}, 4 \mathrm{H}$, Ar-H). ${ }^{13} \mathrm{C}$ NMR (DMSO-d 6 , $\left.400 \mathrm{MHz}\right): 30.1,31.3,33.5,34.2$, 42.6, 43.8, 50.1, 51.4, 123.2, 125.1, 128.2, 129.3, 160.3, 165.3. Ms: $\mathrm{m} / z=304\left(\mathrm{M}^{+\cdot}+1\right)$.

5h: IR (KBr): $3100-3400 \mathrm{~cm}^{-1}$ (broad medium, $-\mathrm{NH}-$ ), $1690 \mathrm{~cm}^{-1}$ (sharp, strong, -CO- of amide group), $1655 \mathrm{~cm}^{-1}$ (sharp, strong, -CO- of amide group); ${ }^{1} \mathrm{H}-\mathrm{NMR}: \delta 1.4(\mathrm{t}, 3 \mathrm{H}$, $\left.-\mathrm{CH}_{3}\right), \delta 1.8\left(\mathrm{t}, 3 \mathrm{H},-\mathrm{CH}_{3}\right), \delta 2.2\left(\mathrm{q}, 2 \mathrm{H},-\mathrm{CH}_{2}\right), \delta 2.8-3.6(\mathrm{t}$, $16 \mathrm{H}$, eight $-\mathrm{CH}_{2}$ groups), 7.0-8.0 (m, $\left.4 \mathrm{H}, \mathrm{Ar}-\mathrm{H}\right) .{ }^{13} \mathrm{C} \mathrm{NMR}$ (DMSO-d ${ }_{6}, 400 \mathrm{MHz}$ ): 13.2, 28.6, 29.5, 32.2, 33.7, 34.5, 35.4, 43.5, 44.5, 53.5, 54.6, 125.5, 126.4, 126.9, 129.5, 161.3, 165.9. Ms: $m / z=345\left(\mathrm{M}^{+\cdot}+1\right)$.

5i: IR (KBr): $3100-3400 \mathrm{~cm}^{-1}$ (broad medium, $-\mathrm{NH}-$ ), $1680 \mathrm{~cm}^{-1}$ (sharp, strong, -CO- of amide group), $1650 \mathrm{~cm}^{-1}$ (sharp, strong, -CO- of amide group); ${ }^{1} \mathrm{H}-\mathrm{NMR}: \delta 1.4(\mathrm{t}$, $\left.3 \mathrm{H},-\mathrm{CH}_{3}\right), \delta 2.2\left(\mathrm{q}, 2 \mathrm{H},-\mathrm{CH}_{2}\right), \delta 2.8-3.6(\mathrm{t}, 16 \mathrm{H}$, eight $\mathrm{CH}_{2}$ groups), 7.0-8.0 (m, 4H, Ar-H). ${ }^{13} \mathrm{C}$ NMR (DMSO-d $\mathrm{d}_{6}$, $400 \mathrm{MHz}): 13.2,29.4,31.2,32.2,33.2,34.5,42.7,44.8,50.9,51.9$, 124.3, 125.9, 127.8, 129.0, 160.7, 168.9. Ms: $m / z=332\left(\mathrm{M}^{+}+1\right)$.

5j: IR (KBr): $3100-3400 \mathrm{~cm}^{-1}$ (broad medium, $-\mathrm{NH}-$ ), $1670 \mathrm{~cm}^{-1}$ (sharp, strong, -CO- of amide group), $1655 \mathrm{~cm}^{-1}$ (sharp, strong, -CO- of amide group); ${ }^{1} \mathrm{H}-\mathrm{NMR}: \delta 1.6(\mathrm{t}, 3 \mathrm{H}$, $\left.-\mathrm{CH}_{3}\right), \delta 2.8-3.6\left(\mathrm{t}, 16 \mathrm{H}\right.$, Eight $-\mathrm{CH}_{2}$ groups), 7.0-8.0 (m, $4 \mathrm{H}$, Ar-H). ${ }^{13} \mathrm{C}$ NMR (DMSO-d 6 , $400 \mathrm{MHz}$ ): 28.4, 33.2, 34.7, 35.4, 39.3, 44.5, 47.6, 53.2, 55.2, 127.1, 128.2, 129.3, 129.9, 163.3, 169.4. Ms: $m / z=318\left(\mathrm{M}^{+\cdot}+1\right)$.

7a: IR (KBr): $3100-3400 \mathrm{~cm}^{-1}$ (broad medium, $-\mathrm{NH}-$ ), $1680 \mathrm{~cm}^{-1}$ (sharp, strong, -CO- of acid group), $1645 \mathrm{~cm}^{-1}$ (sharp, strong, -CO- of amide group); ${ }^{1} \mathrm{H}-\mathrm{NMR}: \delta 1.0(\mathrm{t}$, $\left.6 \mathrm{H},-\mathrm{CH}_{3},-\mathrm{CH}_{3}\right), \delta 3.2\left(\mathrm{q}, 2 \mathrm{H},-\mathrm{CH}_{2}\right), \delta 3.4\left(\mathrm{q}, 2 \mathrm{H},-\mathrm{CH}_{2}\right)$, 7.0-8.0 ( $\mathrm{m}, 9 \mathrm{H}, \mathrm{Ar}-\mathrm{H}), 10.6$ (s, 1H, -NH, D2O exchangeable). ${ }^{13} \mathrm{C}$ NMR (DMSO-d 6 , $400 \mathrm{MHz}$ ): 12.2, 13.4, 37.9, 42.5, 123.4, 126.2, 127.8, 128.1, 128.5, 130.3, 134.1, 137.4, 139.1, 165.8, 169.2. Ms: $m / z=297\left(\mathrm{M}^{+\cdot}+1\right)$.

7b: IR (KBr): $3100-3400 \mathrm{~cm}^{-1}$ (broad medium, $-\mathrm{NH}-$ ), $1680 \mathrm{~cm}^{-1}$ (sharp, strong, -CO- of acid group), $1645 \mathrm{~cm}^{-1}$ (sharp, strong, -CO- of amide group); ${ }^{1} \mathrm{H}-\mathrm{NMR}$ : $\delta 2.2(\mathrm{~s}, 1 \mathrm{H}$, $-\mathrm{NH}), \delta 3.0\left(\mathrm{t}, 2 \mathrm{H},-\mathrm{CH}_{2}\right), \delta 3.2\left(\mathrm{t}, 2 \mathrm{H},-\mathrm{CH}_{2}\right), \delta 3.4(\mathrm{t}, 2 \mathrm{H}$, $\left.-\mathrm{CH}_{2}\right), \delta 3.8\left(\mathrm{t}, 2 \mathrm{H},-\mathrm{CH}_{2}\right), 7.0-8.0(\mathrm{~m}, 9 \mathrm{H}, \mathrm{Ar}-\mathrm{H}), 10.4(\mathrm{~s}, 1 \mathrm{H}$, -NH, D2O exchangeable). ${ }^{13} \mathrm{C}$ NMR (DMSO-d 6 , $\left.400 \mathrm{MHz}\right)$ : 49.3, 50.3, 51.5, 51.3, 124.3, 124.5, 125.5, 126.4 , 127.3, 128.5, 129.5, 129.9, 131.5, 163.2, 164.5. Ms: $m / z=310\left(\mathrm{M}^{+.}+1\right)$.

7c: IR (KBr): $3100-3400 \mathrm{~cm}^{-1}$ (broad medium, $-\mathrm{NH}-$ ), $1690 \mathrm{~cm}^{-1}$ (sharp, strong, -CO- of acid group), $1645 \mathrm{~cm}^{-1}$ (sharp, strong, -CO- of amide group); ${ }^{1} \mathrm{H}-\mathrm{NMR}$ : $\delta 1.2(\mathrm{t}, 3 \mathrm{H}$, $\left.-\mathrm{CH}_{3}\right), \delta 2.6\left(\mathrm{q}, 2 \mathrm{H},-\mathrm{CH}_{2}\right), \delta 3.0\left(\mathrm{t}, 2 \mathrm{H},-\mathrm{CH}_{2}\right), \delta 3.2(\mathrm{t}, 2 \mathrm{H}$, $\left.-\mathrm{CH}_{2}\right), \delta 3.4\left(\mathrm{t}, 2 \mathrm{H},-\mathrm{CH}_{2}\right), \delta 3.8\left(\mathrm{t}, 2 \mathrm{H},-\mathrm{CH}_{2}\right), 7.0-8.0(\mathrm{~m}$, 9H, Ar-H), 10.4 (s, 1H, -NH, D2O exchangeable). ${ }^{13} \mathrm{C}$ NMR (DMSO-d ${ }_{6}, 400 \mathrm{MHz}$ ): 12.6, 44.5, 47.3, 48.5, 50.5, 51.3, 120.3,
$122.7,125.4,126.3,127.7,128.3,129.2,130.9,131.4,160.6,164.9$. Ms: $m / z=338\left(\mathrm{M}^{+}+1\right)$.

7d: IR (KBr): $3100-3400 \mathrm{~cm}^{-1}$ (broad medium, $-\mathrm{NH}-$ ), $1690 \mathrm{~cm}^{-1}$ (sharp, strong, -CO- of acid group), $1655 \mathrm{~cm}^{-1}$ (sharp, strong, -CO- of amide group); ${ }^{1} \mathrm{H}-\mathrm{NMR}$ : $\delta 1.6(\mathrm{t}, 3 \mathrm{H}$, $\left.-\mathrm{CH}_{3}\right), \delta 3.0\left(\mathrm{t}, 2 \mathrm{H},-\mathrm{CH}_{2}\right), \delta 3.2\left(\mathrm{t}, 2 \mathrm{H},-\mathrm{CH}_{2}\right), \delta 3.4(\mathrm{t}, 2 \mathrm{H},-$ $\left.\mathrm{CH}_{2}\right), \delta 3.8\left(\mathrm{t}, 2 \mathrm{H},-\mathrm{CH}_{2}\right), 7.0-8.0(\mathrm{~m}, 9 \mathrm{H}, \mathrm{Ar}-\mathrm{H}), 13.00(\mathrm{~s}, 1 \mathrm{H}$, -NH, D2O exchangeable). ${ }^{13} \mathrm{C}$ NMR (DMSO-d $\left.6,400 \mathrm{MHz}\right)$ : 34.5, 46.4, 47.2, 48.6, 50.2, 121.2, 123.4, 123.9, 124.6, 125.6, 126.3, 128.2, 131.9, 132.4, 164.2, 169.2. Ms: $m / z=324\left(\mathrm{M}^{+}+1\right)$.

7e: IR (KBr): $3100-3400 \mathrm{~cm}^{-1}$ (broad medium, $-\mathrm{NH}-$ ), $1680 \mathrm{~cm}^{-1}$ (sharp, strong, -CO- of acid group), $1660 \mathrm{~cm}^{-1}$ (sharp, strong, -CO- of amide group); ${ }^{1} \mathrm{H}-\mathrm{NMR}: \delta 3.0(\mathrm{t}$, $\left.2 \mathrm{H},-\mathrm{CH}_{2}\right), \delta 3.2\left(\mathrm{t}, 2 \mathrm{H},-\mathrm{CH}_{2}\right), \delta 3.4\left(\mathrm{t}, 2 \mathrm{H},-\mathrm{CH}_{2}\right), \delta 3.8(\mathrm{t}$, $2 \mathrm{H},-\mathrm{CH}_{2}$ ), 7.0-8.0 (m, 8H, Ar-H), 13.00 (s, 1H, -NH, D2O exchangeable). ${ }^{13} \mathrm{C}$ NMR (DMSO- $\mathrm{d}_{6}, 400 \mathrm{MHz}$ ): 50.3, 51.3, $71.5,72.3,120.3,121.2,124.2,125.6,128.1,128.9,129.1,129.9$, 131.4, 165.1, 166.3. Ms: $m / z=311\left(\mathrm{M}^{+\cdot}+1\right)$.

7f: IR (KBr): $3100-3400 \mathrm{~cm}^{-1}$ (broad medium, $-\mathrm{NH}-$ ), $1680 \mathrm{~cm}^{-1}$ (sharp, strong, -CO- of acid group), $1644 \mathrm{~cm}^{-1}$ (sharp, strong, -CO- of amide group); ${ }^{1} \mathrm{H}-\mathrm{NMR}$ : $\delta 1.0(\mathrm{t}, 6 \mathrm{H}$, $\left.-\mathrm{CH}_{3},-\mathrm{CH}_{3}\right), \delta 2.4\left(\mathrm{~s}, 3 \mathrm{H},-\mathrm{CH}_{3}\right), \delta 3.2\left(\mathrm{q}, 2 \mathrm{H},-\mathrm{CH}_{2}\right), \delta$ $3.4\left(\mathrm{q}, 2 \mathrm{H},-\mathrm{CH}_{2}\right), 7.0-8.0(\mathrm{~m}, 8 \mathrm{H}, \mathrm{Ar}-\mathrm{H}), 10.6(\mathrm{~s}, 1 \mathrm{H},-\mathrm{NH}$, D2O exchangeable). ${ }^{13} \mathrm{C}$ NMR (DMSO- $\mathrm{d}_{6}, 400 \mathrm{MHz}$ ): 12.6, 13.8, 19.4, 39.9, 43.6, 123.6, 124.6, 125.2, 126.6, 127.6, 129.8, 131.2, 133.5, 136.5, 166.7, 168.3. Ms: $m / z=311\left(\mathrm{M}^{+}+1\right)$.

7g: IR (KBr): $3100-3400 \mathrm{~cm}^{-1}$ (broad medium, $-\mathrm{NH}-$ ), $1685 \mathrm{~cm}^{-1}$ (sharp, strong, -CO- of acid group), $1655 \mathrm{~cm}^{-1}$ (sharp, strong, -CO- of amide group); ${ }^{1} \mathrm{H}-\mathrm{NMR}$ : $\delta 2.2(\mathrm{~s}, 1 \mathrm{H}$, $-\mathrm{NH}), \delta 2.4\left(\mathrm{~s}, 3 \mathrm{H},-\mathrm{CH}_{3}\right), \delta 3.0\left(\mathrm{t}, 2 \mathrm{H},-\mathrm{CH}_{2}\right), \delta 3.2(\mathrm{t}, 2 \mathrm{H}$, $\left.-\mathrm{CH}_{2}\right), \delta 3.4\left(\mathrm{t}, 2 \mathrm{H},-\mathrm{CH}_{2}\right), \delta 3.8\left(\mathrm{t}, 2 \mathrm{H},-\mathrm{CH}_{2}\right), 7.0-8.0(\mathrm{~m}$, $8 \mathrm{H}, \mathrm{Ar}-\mathrm{H}), 10.6$ (s, 1H, -NH, D2O exchangeable). ${ }^{13} \mathrm{C} \mathrm{NMR}$ (DMSO-d ${ }_{6}, 400 \mathrm{MHz}$ ): 20.5, 44.5, 49.3, 50.5, 51.5, 120.2, 122.4, $123.4,124.5,125.3,126.6,128.5,130.1,133.5,163.7,166.6 . \mathrm{Ms}$ : $m / z=324\left(\mathrm{M}^{+}+1\right)$.

7h: IR (KBr): $3100-3400 \mathrm{~cm}^{-1}$ (broad medium, $-\mathrm{NH}-$ ), $1695 \mathrm{~cm}^{-1}$ (sharp, strong, -CO- of acid group), $1655 \mathrm{~cm}^{-1}$ (sharp, strong, -CO- of amide group); ${ }^{1} \mathrm{H}-\mathrm{NMR}: \delta 1.2(\mathrm{t}, 3 \mathrm{H}$, $\left.-\mathrm{CH}_{3}\right), \delta 2.4\left(\mathrm{~s}, 3 \mathrm{H},-\mathrm{CH}_{3}\right), \delta 2.6\left(\mathrm{q}, 2 \mathrm{H},-\mathrm{CH}_{2}\right), \delta 3.0(\mathrm{t}$, $\left.2 \mathrm{H},-\mathrm{CH}_{2}\right), \delta 3.2\left(\mathrm{t}, 2 \mathrm{H},-\mathrm{CH}_{2}\right), \delta 3.4\left(\mathrm{t}, 2 \mathrm{H},-\mathrm{CH}_{2}\right), \delta 3.8$ $\left(\mathrm{t}, 2 \mathrm{H},-\mathrm{CH}_{2}\right.$ ), 7.0-8.0 (m, 8H, Ar-H), 10.6 (s, 1H, -NH, D2O exchangeable). ${ }^{13} \mathrm{C}$ NMR (DMSO- $\left.\mathrm{d}_{6}, 400 \mathrm{MHz}\right): 12.2,19.3$, 44.2, 47.6, 48.3, 51.2, 52.2, 119.3, 121.3, 124.2, 124.9, 126.2, 127.1, 130.4, 131.3, 132.3, 161.1, 165.1. Ms: $m / z=352\left(\mathrm{M}^{+}+1\right)$.

7i: IR (KBr): $3100-3400 \mathrm{~cm}^{-1}$ (broad medium, $-\mathrm{NH}-$ ), $1680 \mathrm{~cm}^{-1}$ (sharp, strong, -CO- of acid group), $1650 \mathrm{~cm}^{-1}$ (sharp, strong, -CO- of amide group); ${ }^{1} \mathrm{H}-\mathrm{NMR}$ : $\delta 1.6(\mathrm{t}, 3 \mathrm{H}$, $\left.-\mathrm{CH}_{3}\right), \delta 2.4\left(\mathrm{~s}, 3 \mathrm{H},-\mathrm{CH}_{3}\right), \delta 3.0\left(\mathrm{t}, 2 \mathrm{H},-\mathrm{CH}_{2}\right), \delta 3.2(\mathrm{t}, 2 \mathrm{H}$, $\left.-\mathrm{CH}_{2}\right), \delta 3.4\left(\mathrm{t}, 2 \mathrm{H},-\mathrm{CH}_{2}\right), \delta 3.8\left(\mathrm{t}, 2 \mathrm{H},-\mathrm{CH}_{2}\right), 7.0-8.0(\mathrm{~m}$, $8 \mathrm{H}, \mathrm{Ar}-\mathrm{H}), 13.00$ (s, 1H, -NH, D2O exchangeable). ${ }^{13} \mathrm{C}$ NMR (DMSO- $\mathrm{D}_{6}, 400 \mathrm{MHz}$ ): 18.4, 35.4, 45.4, 46.3, 47.3, 51.3, 120.1, 122.2 , 122.6, 124.5, 124.7, 127.4, 128.6, 131.0, 132.8, 164.6, 169.9. Ms: $m / z=338\left(\mathrm{M}^{+\cdot}+1\right)$.

$7 \mathbf{j}$ : IR (KBr): $3100-3400 \mathrm{~cm}^{-1}$ (broad medium, $-\mathrm{NH}-$ ), $1685 \mathrm{~cm}^{-1}$ (sharp, strong, -CO- of acid group), $1650 \mathrm{~cm}^{-1}$ (sharp, strong, -CO- of amide group); ${ }^{1} \mathrm{H}-\mathrm{NMR}: \delta 2.4(\mathrm{~s}, 3 \mathrm{H}$, $\left.-\mathrm{CH}_{3}\right), \delta 3.0\left(\mathrm{t}, 2 \mathrm{H},-\mathrm{CH}_{2}\right), \delta 3.2\left(\mathrm{t}, 2 \mathrm{H},-\mathrm{CH}_{2}\right), \delta 3.4(\mathrm{t}, 2 \mathrm{H},-$ $\left.\mathrm{CH}_{2}\right), \delta 3.8\left(\mathrm{t}, 2 \mathrm{H},-\mathrm{CH}_{2}\right), 7.0-8.0(\mathrm{~m}, 8 \mathrm{H}, \mathrm{Ar}-\mathrm{H}), 13.00(\mathrm{~s}, 1 \mathrm{H}$, 
-NH, D2O exchangeable). ${ }^{13} \mathrm{C}$ NMR (DMSO-d 6 , $400 \mathrm{MHz}$ ): $17.9,51.2,52.0,70.2,72.4,121.2,122.4,125.3,126.0,126.9,127.0$, 129.6, 130.1, 131.5, 160.4, 166.7. Ms: $m / z=325\left(\mathrm{M}^{+.}+1\right)$.

7k: IR (KBr): $3100-3400 \mathrm{~cm}^{-1}$ (broad medium, $-\mathrm{NH}-$ ), $1685 \mathrm{~cm}^{-1}$ (sharp, strong, $-\mathrm{CO}-$ of acid group), $1645 \mathrm{~cm}^{-1}$ (sharp, strong, -CO- of amide group); ${ }^{1} \mathrm{H}-\mathrm{NMR}: \delta 1.1(\mathrm{t}, 6 \mathrm{H}$, $\left.-\mathrm{CH}_{3},-\mathrm{CH}_{3}\right), \delta 2.6\left(\mathrm{~s}, 3 \mathrm{H},-\mathrm{CH}_{3}\right), \delta 3.2\left(\mathrm{q}, 2 \mathrm{H},-\mathrm{CH}_{2}\right), \delta$ $3.4\left(\mathrm{q}, 2 \mathrm{H},-\mathrm{CH}_{2}\right), 7.0-8.0(\mathrm{~m}, 8 \mathrm{H}, \mathrm{Ar}-\mathrm{H}), 10.6(\mathrm{~s}, 1 \mathrm{H},-\mathrm{NH}$, D2O exchangeable). ${ }^{13} \mathrm{C}$ NMR (DMSO- $\left.\mathrm{d}_{6}, 400 \mathrm{MHz}\right): 12.4$, 13.5, 19.6, 40.9, 43.5, 124.6, 125.6, 126.7, 128.6, 129.4, 130.6, 131.2, 136.5, 135.5, 166.9, 168.7. Ms: $m / z=311\left(\mathrm{M}^{+}+1\right)$.

7l: IR (KBr): $3100-3400 \mathrm{~cm}^{-1}$ (broad medium, $-\mathrm{NH}-$ ), $1685 \mathrm{~cm}^{-1}$ (sharp, strong, $-\mathrm{CO}-$ of acid group), $1655 \mathrm{~cm}^{-1}$ (sharp, strong, -CO- of amide group); ${ }^{1} \mathrm{H}-\mathrm{NMR}: \delta 2.4$ (s, $1 \mathrm{H},-\mathrm{NH}), \delta 2.4\left(\mathrm{~s}, 3 \mathrm{H},-\mathrm{CH}_{3}\right), \delta 3.0\left(\mathrm{t}, 2 \mathrm{H},-\mathrm{CH}_{2}\right), \delta 3.4$ $\left(\mathrm{t}, 2 \mathrm{H},-\mathrm{CH}_{2}\right), \delta 3.4\left(\mathrm{t}, 2 \mathrm{H},-\mathrm{CH}_{2}\right), \delta 3.8\left(\mathrm{t}, 2 \mathrm{H},-\mathrm{CH}_{2}\right), 7.0-$ $8.0(\mathrm{~m}, 8 \mathrm{H}, \mathrm{Ar}-\mathrm{H}), 10.6\left(\mathrm{~s}, 1 \mathrm{H},-\mathrm{NH}, \mathrm{D} 2 \mathrm{O}\right.$ exchangeable). ${ }^{13} \mathrm{C}$ NMR (DMSO-d 6 , $400 \mathrm{MHz}$ ): 19.5, 43.4, 45.5, 52.5, 53.4, 119.3, 123.4, 123.9, 124.9, 125.5, 127.6, 128.7, 130.2, 132.5, 161.3, 166.5. Ms: $m / z=324\left(\mathrm{M}^{+}+1\right)$.

7 m: IR (KBr): $3100-3400 \mathrm{~cm}^{-1}$ (broad medium, $-\mathrm{NH}-$ ), $1695 \mathrm{~cm}^{-1}$ (sharp, strong, -CO- of acid group), $1655 \mathrm{~cm}^{-1}$ (sharp, strong, -CO- of amide group); ${ }^{1} \mathrm{H}-\mathrm{NMR}: \delta 1.4(\mathrm{t}, 3 \mathrm{H}$, $\left.-\mathrm{CH}_{3}\right), \delta 2.4\left(\mathrm{~s}, 3 \mathrm{H},-\mathrm{CH}_{3}\right), \delta 2.6\left(\mathrm{q}, 2 \mathrm{H},-\mathrm{CH}_{2}\right), \delta 3.0(\mathrm{t}$, $\left.2 \mathrm{H},-\mathrm{CH}_{2}\right), \delta 3.2\left(\mathrm{t}, 2 \mathrm{H},-\mathrm{CH}_{2}\right), \delta 3.4\left(\mathrm{t}, 2 \mathrm{H},-\mathrm{CH}_{2}\right), \delta 3.8$ $\left(\mathrm{t}, 2 \mathrm{H},-\mathrm{CH}_{2}\right), 7.0-8.0(\mathrm{~m}, 8 \mathrm{H}, \mathrm{Ar}-\mathrm{H}), 10.4(\mathrm{~s}, 1 \mathrm{H},-\mathrm{NH}, \mathrm{D} 2 \mathrm{O}$ exchangeable). ${ }^{13} \mathrm{C}$ NMR (DMSO-d $\mathrm{d}_{6}, 400 \mathrm{MHz}$ ): $11.23,18.2$, 42.1, 43.4, 45.2, 50.8, 51.3, 119.5, 120.4, 124.5, 126.9, 127.4, 126.1, 130.6, 131.3, 132.6, 160.1, 165.6. Ms: $m / z=352\left(\mathrm{M}^{+}+1\right)$.

7n: IR (KBr): $3100-3400 \mathrm{~cm}^{-1}$ (broad medium, $-\mathrm{NH}-$ ), $1683 \mathrm{~cm}^{-1}$ (sharp, strong, $-\mathrm{CO}-$ of acid group), $1650 \mathrm{~cm}^{-1}$ (sharp, strong, -CO- of amide group); ${ }^{1} \mathrm{H}-\mathrm{NMR}: \delta 1.6$ (t, $3 \mathrm{H}$, $\left.-\mathrm{CH}_{3}\right), \delta 2.4\left(\mathrm{~s}, 3 \mathrm{H},-\mathrm{CH}_{3}\right), \delta 3.0\left(\mathrm{t}, 2 \mathrm{H},-\mathrm{CH}_{2}\right), \delta 3.2(\mathrm{t}, 2 \mathrm{H}$, $\left.-\mathrm{CH}_{2}\right), \delta 3.4\left(\mathrm{t}, 2 \mathrm{H},-\mathrm{CH}_{2}\right), \delta 3.8\left(\mathrm{t}, 2 \mathrm{H},-\mathrm{CH}_{2}\right), 7.0-8.0(\mathrm{~m}$, $8 \mathrm{H}, \mathrm{Ar}-\mathrm{H}), 13.00$ (s, $1 \mathrm{H},-\mathrm{NH}, \mathrm{D} 2 \mathrm{O}$ exchangeable). ${ }^{13} \mathrm{C}$ NMR (DMSO-d ${ }_{6}, 400 \mathrm{MHz}$ ): 18.3, 36.3, 43.5, 45.2, 46.2, 50.2, 121.2, 121.1, 122.4, 124.4, 125.6, 126.3, 127.2, 130.0, 131.4, 162.6, 166.8 . Ms: $m / z=338\left(\mathrm{M}^{+}+1\right)$.

7o: IR (KBr): $3100-3400 \mathrm{~cm}^{-1}$ (broad medium, $-\mathrm{NH}-$ ), $1685 \mathrm{~cm}^{-1}$ (sharp, strong, $-\mathrm{CO}-$ of acid group), $1650 \mathrm{~cm}^{-1}$ (sharp, strong, -CO- of amide group); ${ }^{1} \mathrm{H}-\mathrm{NMR}: \delta 2.4(\mathrm{~s}, 3 \mathrm{H}$, $\left.-\mathrm{CH}_{3}\right), \delta 3.0\left(\mathrm{t}, 2 \mathrm{H},-\mathrm{CH}_{2}\right), \delta 3.2\left(\mathrm{t}, 2 \mathrm{H},-\mathrm{CH}_{2}\right), \delta 3.4(\mathrm{t}, 2 \mathrm{H},-$ $\left.\mathrm{CH}_{2}\right), \delta 3.8\left(\mathrm{t}, 2 \mathrm{H},-\mathrm{CH}_{2}\right), 7.0-8.0(\mathrm{~m}, 8 \mathrm{H}, \mathrm{Ar}-\mathrm{H}), 13.00(\mathrm{~s}, 1 \mathrm{H}$, -NH, D2O exchangeable). ${ }^{13} \mathrm{C}$ NMR (DMSO-d 6 , $400 \mathrm{MHz}$ ): $18.5,50.1,51.6,73.5,74.3,119.2,120.2,121.2,122.1,123.4,124.1$, 125.3, 127.3, 128.3, 163.5, 167.4. Ms: $m / z=325\left(\mathrm{M}^{+}+1\right)$.

7p: IR (KBr): $3100-3400 \mathrm{~cm}^{-1}$ (broad medium, $-\mathrm{NH}-$ ), $1670 \mathrm{~cm}^{-1}$ (sharp, strong, $-\mathrm{CO}-$ of acid group), $1655 \mathrm{~cm}^{-1}$ (sharp, strong, -CO- of amide group); ${ }^{1} \mathrm{H}-\mathrm{NMR}: \delta 1.0$ (t, $6 \mathrm{H}$, $\left.-\mathrm{CH}_{3},-\mathrm{CH}_{3}\right), \delta 2.4\left(\mathrm{~s}, 3 \mathrm{H},-\mathrm{CH}_{3}\right), \delta 3.2\left(\mathrm{q}, 2 \mathrm{H},-\mathrm{CH}_{2}\right), \delta 3.4$ (q, $\left.2 \mathrm{H},-\mathrm{CH}_{2}\right), 7.0-8.0(\mathrm{~m}, 8 \mathrm{H}, \mathrm{Ar}-\mathrm{H}), 10.6$ (s, $1 \mathrm{H},-\mathrm{NH}, \mathrm{D} 2 \mathrm{O}$ exchangeable). ${ }^{13} \mathrm{C}$ NMR (DMSO-d ${ }_{6}, 400 \mathrm{MHz}$ ): 12.4, 14.4, 32.9, 40.5, 121.4, 125.8, 126.8, 129.1, 130.3, 131.4, 134.6, 138.4, 139.9, 163.6, 169.9. Ms: $m / z=331\left(\mathrm{M}^{+}+1\right)$.

7q: IR (KBr): $3100-3400 \mathrm{~cm}^{-1}$ (broad medium, $-\mathrm{NH}-$ ), $1684 \mathrm{~cm}^{-1}$ (sharp, strong, -CO- of acid group), $1650 \mathrm{~cm}^{-1}$ (sharp, strong, -CO- of amide group); ${ }^{1} \mathrm{H}-\mathrm{NMR}: \delta 2.2(\mathrm{~s}, 1 \mathrm{H}$, $-\mathrm{NH}), \delta 2.4\left(\mathrm{~s}, 3 \mathrm{H},-\mathrm{CH}_{3}\right), \delta 3.0\left(\mathrm{t}, 2 \mathrm{H},-\mathrm{CH}_{2}\right), \delta 3.2(\mathrm{t}, 2 \mathrm{H}$,
$\left.-\mathrm{CH}_{2}\right), \delta 3.4\left(\mathrm{t}, 2 \mathrm{H},-\mathrm{CH}_{2}\right), \delta 3.8\left(\mathrm{t}, 2 \mathrm{H},-\mathrm{CH}_{2}\right), 7.0-8.0(\mathrm{~m}$, $8 \mathrm{H}, \mathrm{Ar}-\mathrm{H}), 10.4\left(\mathrm{~s}, 1 \mathrm{H},-\mathrm{NH}, \mathrm{D} 2 \mathrm{O}\right.$ exchangeable). ${ }^{13} \mathrm{C}$ NMR (DMSO-d ${ }_{6}, 400 \mathrm{MHz}$ ): 44.5, 44.9, 53.2, 54.2, 119.6, 120.5, 121.9, $122.9,127.5,128.5,129.6,130.2,131.3,162.4,164.2 . \mathrm{Ms}: \mathrm{m} / z=$ $344\left(\mathrm{M}^{+}+1\right)$.

7r: IR (KBr): $3100-3400 \mathrm{~cm}^{-1}$ (broad medium, $-\mathrm{NH}-$ ), $1650 \mathrm{~cm}^{-1}$ (sharp, strong, -CO- of acid group), $1640 \mathrm{~cm}^{-1}$ (sharp, strong, -CO- of amide group); ${ }^{1} \mathrm{H}-\mathrm{NMR}: \delta 1.2(\mathrm{t}, 3 \mathrm{H}$, $\left.-\mathrm{CH}_{3}\right), \delta 2.4\left(\mathrm{~s}, 3 \mathrm{H},-\mathrm{CH}_{3}\right), \delta 2.6\left(\mathrm{q}, 2 \mathrm{H},-\mathrm{CH}_{2}\right), \delta 3.0(\mathrm{t}$, $\left.2 \mathrm{H},-\mathrm{CH}_{2}\right), \delta 3.2\left(\mathrm{t}, 2 \mathrm{H},-\mathrm{CH}_{2}\right), \delta 3.4\left(\mathrm{t}, 2 \mathrm{H},-\mathrm{CH}_{2}\right), \delta 3.8$ $\left(\mathrm{t}, 2 \mathrm{H},-\mathrm{CH}_{2}\right), 7.0-8.0(\mathrm{~m}, 8 \mathrm{H}, \mathrm{Ar}-\mathrm{H}), 10.4(\mathrm{~s}, 1 \mathrm{H},-\mathrm{NH}, \mathrm{D} 2 \mathrm{O}$ exchangeable). ${ }^{13} \mathrm{C}$ NMR (DMSO-d 6 , $400 \mathrm{MHz}$ ): 12.8, 44.2, 45.4, 46.2, 51.8, 52.4, 119.6, 121.5, 124.5, 125.6, 127.3, 125.6, 130.2, 132.4, 135.7, 160.7, 165.9. Ms: $m / z=372\left(\mathrm{M}^{+}+1\right)$.

7s: IR (KBr): $3100-3400 \mathrm{~cm}^{-1}$ (broad medium, $-\mathrm{NH}-$ ), $1640 \mathrm{~cm}^{-1}$ (sharp, strong, -CO- of acid group), $1635 \mathrm{~cm}^{-1}$ (sharp, strong, -CO- of amide group); ${ }^{1} \mathrm{H}-\mathrm{NMR}: \delta 1.6(\mathrm{t}, 3 \mathrm{H}$, $\left.-\mathrm{CH}_{3}\right), \delta 2.4\left(\mathrm{~s}, 3 \mathrm{H},-\mathrm{CH}_{3}\right), \delta 3.0\left(\mathrm{t}, 2 \mathrm{H},-\mathrm{CH}_{2}\right), \delta 3.2(\mathrm{t}, 2 \mathrm{H}$, $\left.-\mathrm{CH}_{2}\right), \delta 3.4\left(\mathrm{t}, 2 \mathrm{H},-\mathrm{CH}_{2}\right), \delta 3.8\left(\mathrm{t}, 2 \mathrm{H},-\mathrm{CH}_{2}\right), 7.0-8.0(\mathrm{~m}$, $8 \mathrm{H}, \mathrm{Ar}-\mathrm{H}), 13.00\left(\mathrm{~s}, 1 \mathrm{H},-\mathrm{NH}, \mathrm{D} 2 \mathrm{O}\right.$ exchangeable). ${ }^{13} \mathrm{C}$ NMR (DMSO-d ${ }_{6}, 400 \mathrm{MHz}$ ):38.3, 45.6, 46.2, 47.5, 50.6, 123.2, 126.6, 127.3, 128.3, 129.1, 129.9, 130.2, 131.4, 132.4, 160.3, 166.4. Ms: $m / z=358\left(\mathrm{M}^{+}+1\right)$.

7t: IR (KBr): $3100-3400 \mathrm{~cm}^{-1}$ (broad medium, $-\mathrm{NH}-$ ), $1690 \mathrm{~cm}^{-1}$ (sharp, strong, $-\mathrm{CO}-$ of acid group), $1650 \mathrm{~cm}^{-1}$ (sharp, strong, -CO- of amide group); ${ }^{1} \mathrm{H}-\mathrm{NMR}: \delta 2.4$ (s, $3 \mathrm{H}$, $\left.-\mathrm{CH}_{3}\right), \delta 3.0\left(\mathrm{t}, 2 \mathrm{H},-\mathrm{CH}_{2}\right), \delta 3.2\left(\mathrm{t}, 2 \mathrm{H},-\mathrm{CH}_{2}\right), \delta 3.4(\mathrm{t}, 2 \mathrm{H},-$ $\left.\mathrm{CH}_{2}\right), \delta 3.8\left(\mathrm{t}, 2 \mathrm{H},-\mathrm{CH}_{2}\right), 7.0-8.0(\mathrm{~m}, 8 \mathrm{H}, \mathrm{Ar}-\mathrm{H}), 13.00(\mathrm{~s}, 1 \mathrm{H}$, -NH, D2O exchangeable). ${ }^{13} \mathrm{C}$ NMR (DMSO-d 6 , $400 \mathrm{MHz}$ ): 48.1, 50.6, 72.5, 73.1, 119.5, 120.6, 122.3, 122.9, 123.5, 124.3, 125.7, 126.3, 129.3, 165.7, 169.4. Ms: $m / z=345\left(\mathrm{M}^{+\cdot}+1\right)$.

7u: IR (KBr): $3100-3400 \mathrm{~cm}^{-1}$ (broad medium, $-\mathrm{NH}-$ ), $1680 \mathrm{~cm}^{-1}$ (sharp, strong, -CO- of acid group), $1650 \mathrm{~cm}^{-1}$ (sharp, strong, -CO- of amide group); ${ }^{1} \mathrm{H}-\mathrm{NMR}: \delta 1.0$ (t, $6 \mathrm{H}$, $\left.-\mathrm{CH}_{3},-\mathrm{CH}_{3}\right), \delta 2.4\left(\mathrm{~s}, 3 \mathrm{H},-\mathrm{CH}_{3}\right), \delta 3.2\left(\mathrm{q}, 2 \mathrm{H},-\mathrm{CH}_{2}\right), \delta 3.4$ (q, $\left.2 \mathrm{H},-\mathrm{CH}_{2}\right), 7.0-8.0(\mathrm{~m}, 9 \mathrm{H}, \mathrm{Ar}-\mathrm{H}), 10.6(\mathrm{~s}, 1 \mathrm{H},-\mathrm{NH}, \mathrm{D} 2 \mathrm{O}$ exchangeable). ${ }^{13} \mathrm{C}$ NMR (DMSO-d $\left.6.400 \mathrm{MHz}\right): 12.5,15.4$, $37.9,43.5,125.4,126.5,126.8,129.6,131.2,131.3,135.6,138.6$, 139.3, 164.6, 169.8. Ms: $m / z=375\left(\mathrm{M}^{+}+1\right)$.

$7 \mathrm{v}$ : IR (KBr): $3100-3400 \mathrm{~cm}^{-1}$ (broad medium, $-\mathrm{NH}-$ ), $1687 \mathrm{~cm}^{-1}$ (sharp, strong, -CO- of acid group), $1655 \mathrm{~cm}^{-1}$ (sharp, strong, -CO- of amide group); ${ }^{1} \mathrm{H}-\mathrm{NMR}: \delta 2.2(\mathrm{~s}, 1 \mathrm{H}$, $-\mathrm{NH}), \delta 2.4\left(\mathrm{~s}, 3 \mathrm{H},-\mathrm{CH}_{3}\right), \delta 3.0\left(\mathrm{t}, 2 \mathrm{H},-\mathrm{CH}_{2}\right), \delta 3.2(\mathrm{t}, 2 \mathrm{H}$, $\left.-\mathrm{CH}_{2}\right), \delta 3.4\left(\mathrm{t}, 2 \mathrm{H},-\mathrm{CH}_{2}\right), \delta 3.8\left(\mathrm{t}, 2 \mathrm{H},-\mathrm{CH}_{2}\right), 7.0-8.0(\mathrm{~m}$, $9 \mathrm{H}, \mathrm{Ar}-\mathrm{H}), 13.00\left(\mathrm{~s}, 1 \mathrm{H},-\mathrm{NH}, \mathrm{D} 2 \mathrm{O}\right.$ exchangeable). ${ }^{13} \mathrm{C}$ NMR (DMSO-d ${ }_{6}, 400 \mathrm{MHz}$ ): 41.5, 45.9, 52.3, 54.5, 118.4, 121.3, 125.9, 126.9, 127.7, 128.4, 129.7, 131.4, 133.5, 165.4, 167.7. Ms: $m / z=388$ $\left(\mathrm{M}^{+\cdot}+1\right)$.

7w: IR (KBr): $3100-3400 \mathrm{~cm}^{-1}$ (broad medium, $-\mathrm{NH}-$ ), $1681 \mathrm{~cm}^{-1}$ (sharp, strong, -CO- of acid group), $1655 \mathrm{~cm}^{-1}$ (sharp, strong, -CO- of amide group); ${ }^{1} \mathrm{H}-\mathrm{NMR}: \delta 1.2(\mathrm{t}, 3 \mathrm{H}$, $\left.-\mathrm{CH}_{3}\right), \delta 2.4\left(\mathrm{~s}, 3 \mathrm{H},-\mathrm{CH}_{3}\right), \delta 2.6\left(\mathrm{q}, 2 \mathrm{H},-\mathrm{CH}_{2}\right), \delta 3.0(\mathrm{t}$, $\left.2 \mathrm{H},-\mathrm{CH}_{2}\right), \delta 3.2\left(\mathrm{t}, 2 \mathrm{H},-\mathrm{CH}_{2}\right), \delta 3.4\left(\mathrm{t}, 2 \mathrm{H},-\mathrm{CH}_{2}\right), \delta 3.8$ $\left(\mathrm{t}, 2 \mathrm{H},-\mathrm{CH}_{2}\right), 7.0-8.0(\mathrm{~m}, 9 \mathrm{H}, \mathrm{Ar}-\mathrm{H}), 10.4(\mathrm{~s}, 1 \mathrm{H},-\mathrm{NH}, \mathrm{D} 2 \mathrm{O}$ exchangeable). ${ }^{13} \mathrm{C}$ NMR (DMSO- $\mathrm{d}_{6}, 400 \mathrm{MHz}$ ): 12.4, 43.5, 45.7, 47.3, 52.9, 53.4, 118.4, 121.6, 124.7, 125.5, 128.3, 129.5, 130.5, 131.3, 135.4, 164.5, 165.9. Ms: $m / z=416\left(\mathrm{M}^{+.}+1\right)$. 
7x: IR (KBr): $3100-3400 \mathrm{~cm}^{-1}$ (broad medium, $-\mathrm{NH}-$ ), $1690 \mathrm{~cm}^{-1}$ (sharp, strong, $-\mathrm{CO}-$ of acid group), $1658 \mathrm{~cm}^{-1}$ (sharp, strong, -CO- of amide group); ${ }^{1} \mathrm{H}-\mathrm{NMR}: \delta 1.6(\mathrm{t}$, $\left.3 \mathrm{H},-\mathrm{CH}_{3}\right), \delta 2.4\left(\mathrm{~s}, 3 \mathrm{H},-\mathrm{CH}_{3}\right), \delta 3.0\left(\mathrm{t}, 2 \mathrm{H},-\mathrm{CH}_{2}\right), \delta 3.2$ $\left(\mathrm{t}, 2 \mathrm{H},-\mathrm{CH}_{2}\right), \delta 3.4\left(\mathrm{t}, 2 \mathrm{H},-\mathrm{CH}_{2}\right), \delta 3.8\left(\mathrm{t}, 2 \mathrm{H},-\mathrm{CH}_{2}\right), 7.0-$ 8.0 (m, 9H, Ar-H), 13.00 (s, 1H, -NH, D2O exchangeable). ${ }^{13}$ C NMR (DMSO-d ${ }_{6}, 400 \mathrm{MHz}$ ): 39.2, 46.4, 47.3, 48.4, 49.5, 121.2, 124.3, 124.9, 125.7, 126.4, 128.3, 130.6, 131.1, 131.3, 166.1, 169.3. Ms: $m / z=402\left(\mathrm{M}^{+}+1\right)$.

7y: IR (KBr): $3100-3400 \mathrm{~cm}^{-1}$ (broad medium, $-\mathrm{NH}-$ ), $1675 \mathrm{~cm}^{-1}$ (sharp, strong, $-\mathrm{CO}-$ of acid group), $1635 \mathrm{~cm}^{-1}$ (sharp, strong, -CO- of amide group); ${ }^{1} \mathrm{H}-\mathrm{NMR}: \delta 2.4$ (s, $3 \mathrm{H}$, $\left.-\mathrm{CH}_{3}\right), \delta 3.0\left(\mathrm{t}, 2 \mathrm{H},-\mathrm{CH}_{2}\right), \delta 3.2\left(\mathrm{t}, 2 \mathrm{H},-\mathrm{CH}_{2}\right), \delta 3.4(\mathrm{t}, 2 \mathrm{H},-$ $\left.\mathrm{CH}_{2}\right), \delta 3.8\left(\mathrm{t}, 2 \mathrm{H},-\mathrm{CH}_{2}\right), 7.0-8.0(\mathrm{~m}, 9 \mathrm{H}, \mathrm{Ar}-\mathrm{H}), 13.00(\mathrm{~s}, 1 \mathrm{H}$, -NH, D2O exchangeable). ${ }^{13} \mathrm{C}$ NMR (DMSO-d 6 , $400 \mathrm{MHz}$ ): 48.9, 51.4, 73.5, 74.5, 119.6, 121.4, 122.5, 123.8, 124.7, 125.7, 126.4, 127.3, 129.3, 165.8, 169.3. Ms: $m / z=389\left(\mathrm{M}^{+}+1\right)$.

\section{Conflict of Interests}

The authors declare that there is no conflict of interests regarding the publication of this paper.

\section{Acknowledgment}

The authors are thankful to the authorities of Jawaharlal Nehru Technological University Hyderabad for providing laboratory facilities and for financial support to two of the authors (Padam Praveen Kumar and Yervala Dathu Reddy).

\section{References}

[1] O. R. Louis and R. G. Harry, "Alcoholysis of alkyl benzyl esters of phthalic acid," The Journal of Organic Chemistry, vol. 24, no. 12, pp. 1997-2000, 1959.

[2] P. K. Dubey, S. M. G. Mohiuddin, and D. Ramesh, "Reactions of phthalic anhydride with alcohols," Asian Journal of Chemistry, vol. 9, no. 3, pp. 379-387, 1997.

[3] P. A. Kober, J. T. Marshall, and E. N. Rosenfeld, "Phenolphthalein and its colorless salts. [Third paper.]. Preparation of monobasic phenolphthalates," Journal of the American Chemical Society, vol. 34, no. 10, pp. 1424-1433, 1912.

[4] D. Williamm, "Salts of phenolphthalein," Journal of the American Chemical Society, vol. 54, no. 7, pp. 2947-2951, 1932.

[5] S. A. Carlson and D. M. Hercules, "Delayed thermal fluorescence of anthraquinone in solutions," Journal of the American Chemical Society, vol. 93, no. 22, pp. 5611-5616, 1971.

[6] L. Lunazzi, M. Mancinelli, and A. Mazzani, "Stereodynamics and conformational chirality of the atropisomers of ditolyl anthrones and anthraquinone," The Journal of Organic Chemistry, vol. 73, no. 14, pp. 5354-5359, 2008.

[7] D. Guay, G. Tourillon, L. Gastonguay et al., "Highly photoactive chemically modified thin films of chloroaluminum (and bromoaluminum) phthalocyanines probed by NEXAFS and UPS: determination of the electronic structure and the molecular orientation," Journal of Physical Chemistry, vol. 95, no. 1, pp. 251257, 1991.

[8] P. K. Dubey, S. M. G. Mohiuddin, and D. Ramesh, "Assay of phthalic anhydride and some related compounds by volumetric methods," Asian Journal of Chemistry, vol. 7, no. 3, pp. 597-603, 1995.

[9] L. O. Okunrobo, C. O. Usifoh, and S. O. Okpo, "Reactions of phthalimides with 1-methylethylamine: analgesic and antiinflammatory properties of resulting carboxamides," Pakistan Journal of Pharmaceutical Sciences, vol. 19, no. 1, pp. 34-38, 2006.

[10] V. K. Pandey and N. Raj, "Synthesis of $\alpha$-methylarylamido- $\beta$ naphthyl-(1-methylamino-2-methyl-benzimi-dazolyl)-ethers," Current Science, vol. 53, no. 5, pp. 256-258, 1984.

[11] A. M. Alaa and A. Abdel, "Novel and versatile methodology for synthesis of cyclic imides and evaluation of their cytotoxic, DNA binding, apoptotic inducing activities and molecular modeling study," European Journal of Medicinal Chemistry, vol. 42, no. 5, pp. 614-626, 2007.

[12] F. L. Dunlap and F. W. Cummer, "The action of the sodium salts of dibasic acids on aniline hydrochloride, and of aniline on phthalyl chloride and succinyl chloride," Journal of the American Chemical Society, vol. 25, no. 6, pp. 612-621, 1903.

[13] A. T. Dann, W. Davies, A. N. Hambly, R. E. Paul, and G. S. C. Semmens, "Phthalyl fluoride," Journal of the Chemical Society, pp. 15-21, 1933.

[14] E. G. D. de Toranzo and J. A. Brieux, "Syntheses of unsymmetric o-phthalic acid diamides," Journal of Medicinal Chemistry, vol. 10, no. 5, pp. 982-983, 1967.

[15] A. Reynolds, "Synthesis and characterization of some toluides of o-phthalic acid," The Journal of Organic Chemistry, vol. 28, no. 11, pp. 3223-3225, 1963.

[16] A. El-Faham and F. Albericio, "Peptide couplingreagents, more than a letter soup," Chemical Reviews, vol. 111, no. 11, pp. 65576602, 2011.

[17] L. A. Carpino and A. El-Faham, "Tetramethylfluoroformamidinium hexafluorophosphate: a rapid-acting peptide coupling reagent for solution and solid phase peptide synthesis," Journal of the American Chemical Society, vol. 117, no. 19, pp. 5401-5402, 1995.

[18] R. Subiros-Funosas, G. A. Acosta, A. El-Faham, and F. Albericio, "Microwave irradiation and COMU: a potent combination for solid-phase peptide synthesis," Tetrahedron Letters, vol. 50, no. 45, pp. 6200-6202, 2009.

[19] S.-Y. Han and Y.-A. Kim, "Recent development of peptide coupling reagents in organic synthesis," Tetrahedron, vol. 60, no. 11, pp. 2447-2467, 2004. 

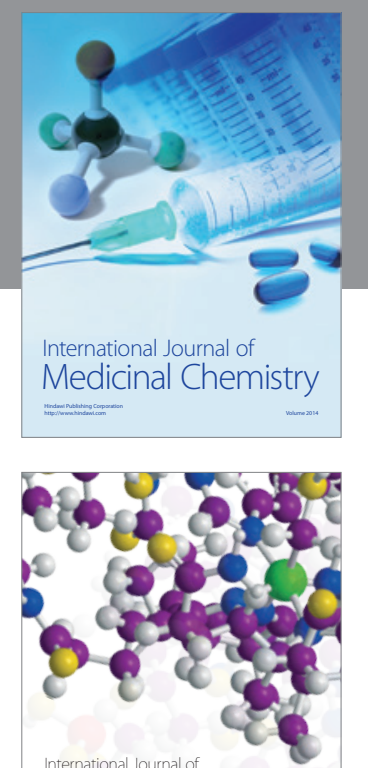

\section{Carbohydrate} Chemistry

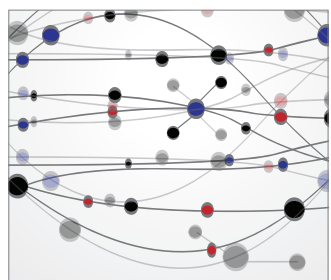

The Scientific World Journal
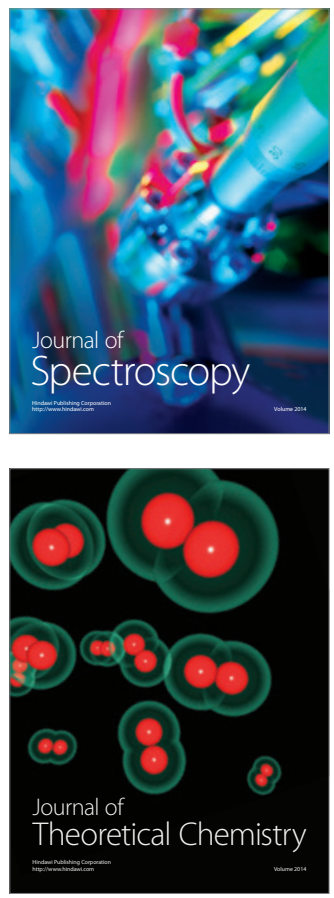
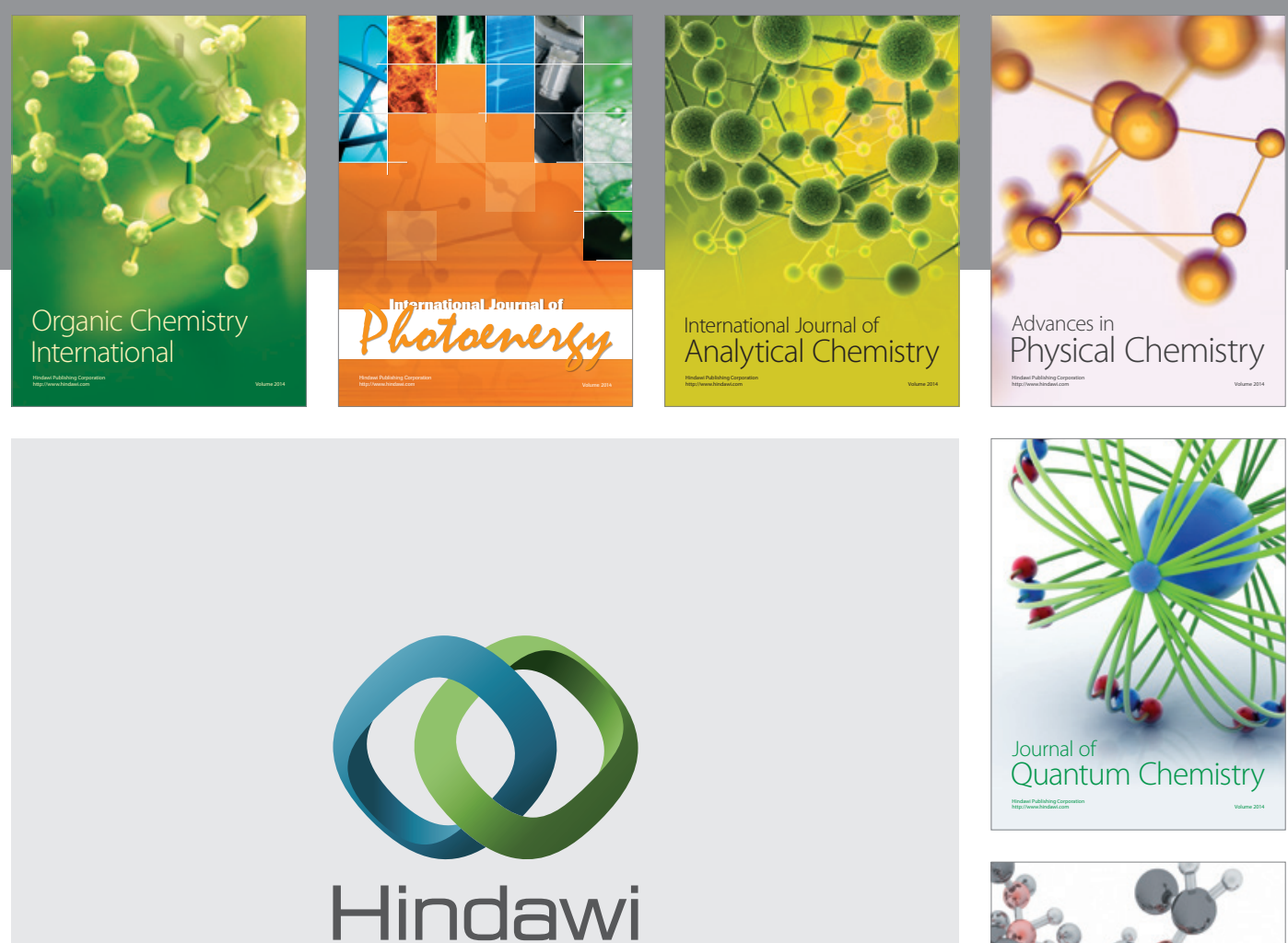

Submit your manuscripts at

http://www.hindawi.com

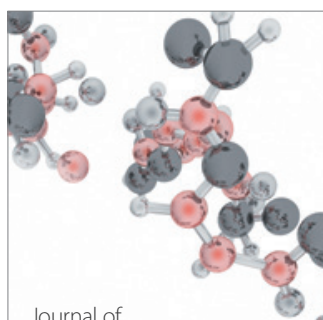

Analytical Methods

in Chemistry

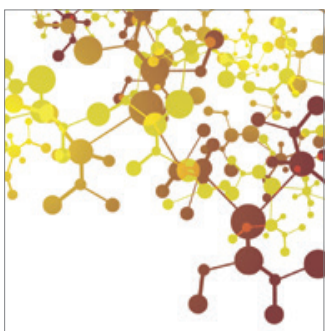

Journal of

Applied Chemistry

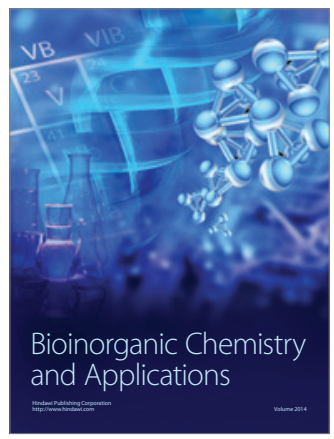

Inorganic Chemistry
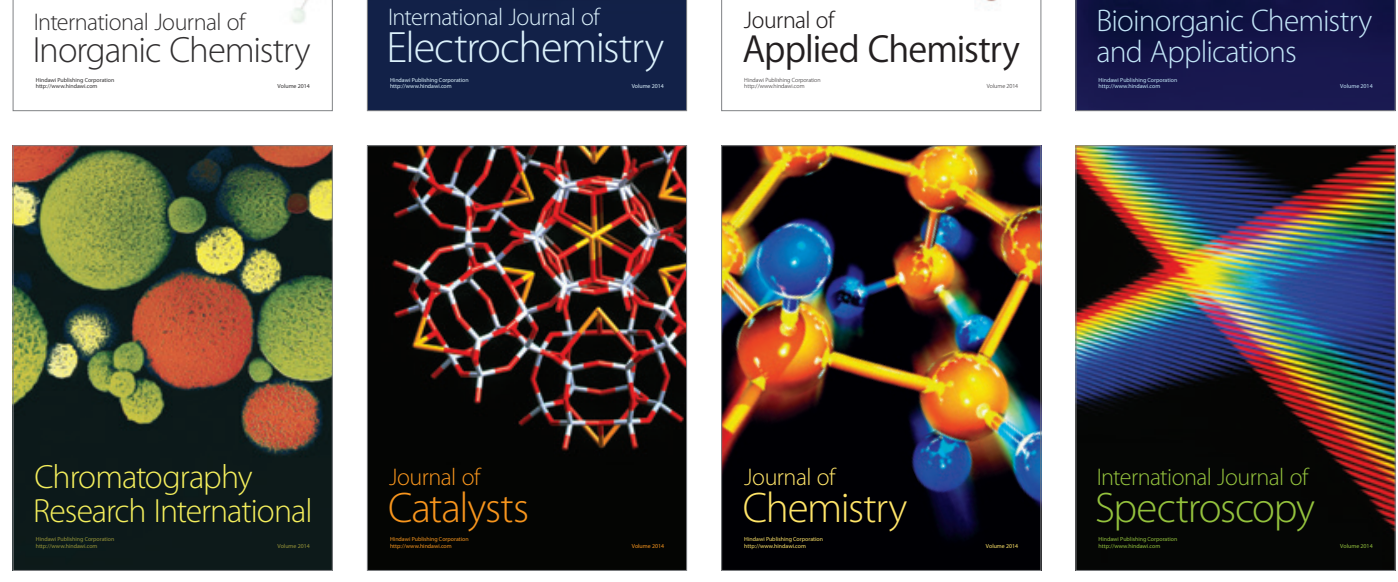